Keywords: Strontium, neptunium, sorption transport

Retention: Permanent

\title{
Laboratory and Lysimeter Experimentation and Transport Modeling of Neptunium and Strontium in Savannah River Site Sediments
}

Todd J. Miller ${ }^{\mathrm{a}}$, Daniel I. Kaplan, and B. A. Powell ${ }^{\mathrm{a}}$

${ }^{a}$ Clemson University

September 2012

Savannah River National Laboratory Savannah River Nuclear Solutions, LLC Aiken, SC 29808 
SRNL-STI-2012-00052

Revision 0

\section{DISCLAIMER}

This work was prepared under an agreement with and funded by the U.S. Government. Neither the U.S. Government or its employees, nor any of its contractors, subcontractors or their employees, makes any express or implied:

1. warranty or assumes any legal liability for the accuracy, completeness, or for the use or results of such use of any information, product, or process disclosed; or

2. representation that such use or results of such use would not infringe privately owned rights; or

3. endorsement or recommendation of any specifically identified commercial product, process, or service.

Any views and opinions of authors expressed in this work do not necessarily state or reflect those of the United States Government, or its contractors, or subcontractors.

\section{Printed in the United States of America}

Prepared for

U.S. Department of Energy 


\section{EXECUTIVE SUMMARY}

The Savannah River Site (SRS) conducts performance assessment (PA) calculations to determine the appropriate amount of low-level radiological waste that can be safely disposed on site. Parameters are included in these calculations that account for the interaction between the immobile solid phase and the mobile aqueous phase. These parameters are either the distribution coefficient $\left(\mathrm{K}_{\mathrm{d}}\right.$ value $)$ or the apparent solubility value $\left(\mathrm{K}_{\mathrm{sp}}\right)$. These parameters are readily found in the literature and are used throughout the DOE complex. One shortcoming of $\mathrm{K}_{\mathrm{d}}$ values is that they are only applicable to a given set of solid and aqueous phase conditions. Therefore, a given radionuclide may have several $K_{d}$ values as it moves between formations and comes into contact with different solids and different aqueous phases.

It is expected that the $K_{d}$ construct will be appropriate to use for a majority of the PA and for a majority of the radionuclides. However, semi-mechanistic models would be more representative in isolated cases where the chemistry is especially transitory or the radionuclide chemistry is especially complex, bringing to bear multiple species of varying sorption tendencies to the sediment. Semimechanistic models explicitly accommodate the dependency of $\mathrm{K}_{\mathrm{d}}$ values, or other sorption parameters, on contaminant concentration, competing ion concentrations, $\mathrm{pH}$-dependent surface charge on the adsorbent, and solute species distribution. Incorporating semi-mechanistic concepts into geochemical models is desirable to make the models more robust and technically defensible. Furthermore, these alternative models could be used to augment or validate a $\mathrm{K}_{d}$-based DOE Order 435.1 Performance Assessment.

The objectives of this study were to: 1) develop a quantitative thermodynamically-based model for neptunium sorption to SRS sediments, and 2) determine a sorption constant from an SRS 11-year lysimeter study. The modeling studies were conducted with existing data sets. The first data set used laboratory generated $\mathrm{Np}$ sorption data as a function of concentration (three orders of magnitude) and as a function of $\mathrm{pH}$ (four orders of magnitude of proton concentration). In this modeling exercise, a very simple solution was identified by assuming that all sorption occurred only to the iron oxides in the sediment and that all the added $\mathrm{NpO}_{4}{ }^{-}$remained in the oxidized state and was not reduced to the $\mathrm{Np}$ (IV) state (as occurs rapidly with $\mathrm{Pu}(\mathrm{V})$ ). With rather limited input data, very good agreement between experimental and modeling results was observed. This modeling approach would be easy to add to the PA with little additional data requirements. This model would be useful in a system where $\mathrm{pH}$ is expected to change greatly, such as directly beneath a grout or concrete structure.

The second model discussed in the report was to derive strontium $\mathrm{K}_{\mathrm{d}}$ values from data collected in an 11-year-old field transport study. In this controlled lysimeter study, a sensitivity analysis was conducted of hydrological and chemical processes that influence contaminant transport, including diffusion coefficients, seepage velocity, and $\mathrm{K}_{\mathrm{d}}$ value. The best overall $\mathrm{K}_{\mathrm{d}}$ derived from the model fit to the data was $32 \mathrm{~L} \mathrm{~kg}^{-1}$, which was the same value that was previously measured in traditional laboratory batch sorption studies. This was an unexpected result given the differences in experimental conditions between the batch test and the lysimeter flow through test, in particular the differences between strontium adsorption and desorption processes occurring in the latter test and not in the former. There were some trends in the lysimeter strontium data that were not predicted by the $\mathrm{K}_{\mathrm{d}}$ model, which suggest that other geochemical processes are likely also controlling strontium transport. Strontium release and cation exchange are being evaluated. These results suggest that future modeling efforts (e.g., PAs) could be improved by employing a more robust semi-empirical modeling approach to transient or complex conditions. 


\section{TABLE OF CONTENTS}

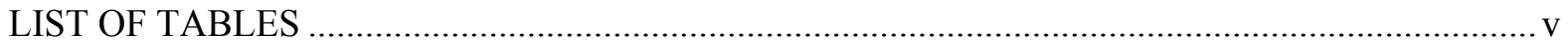

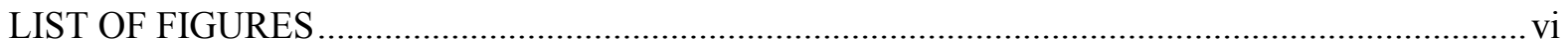

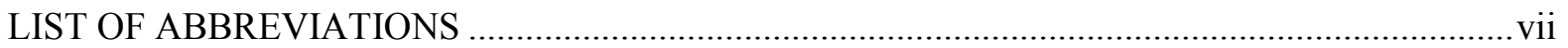

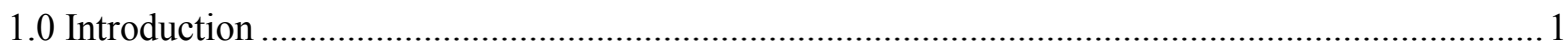

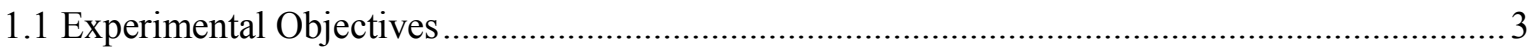

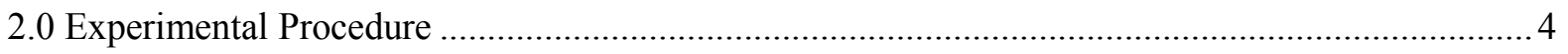

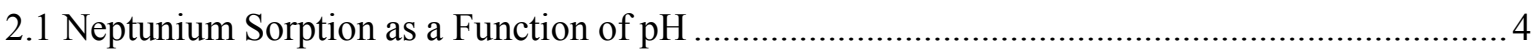

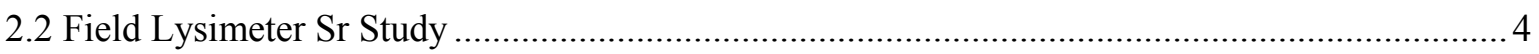

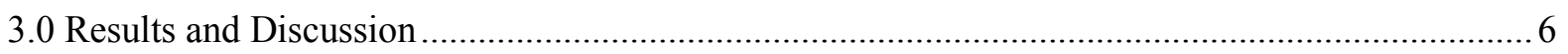

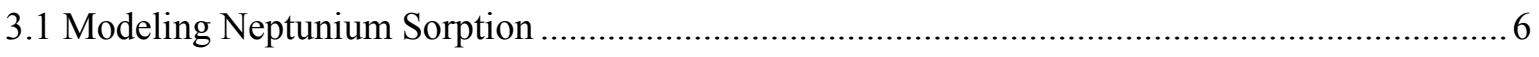

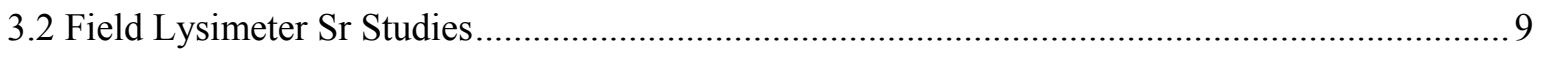

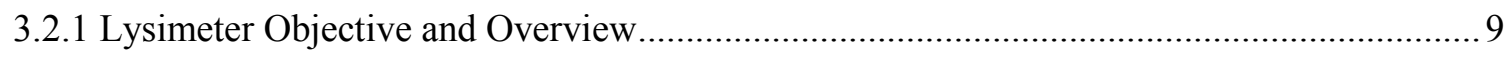

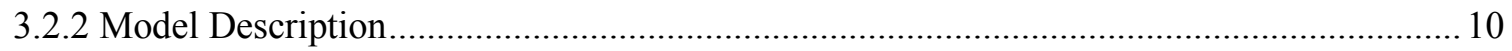

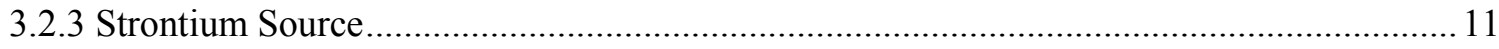

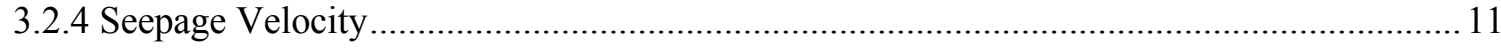

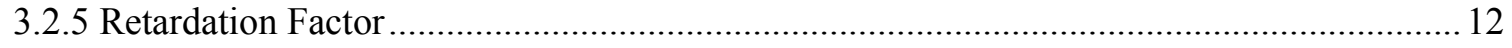

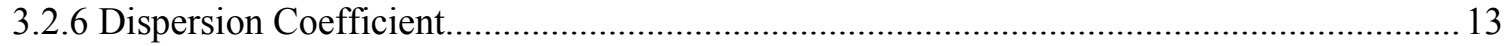

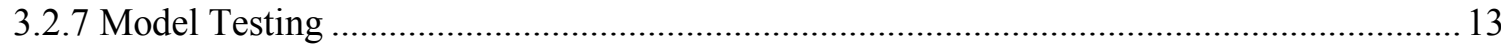

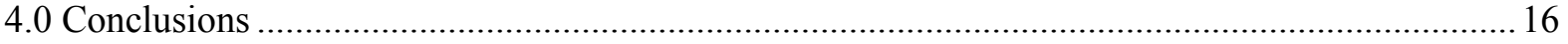

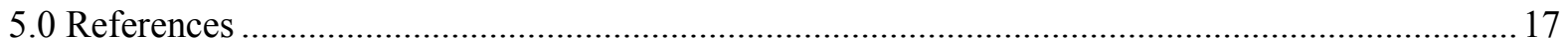

Appendix A: Materials and Methods for the Neptunium Laboratory Sorption Study .......................20

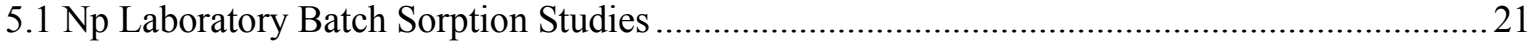

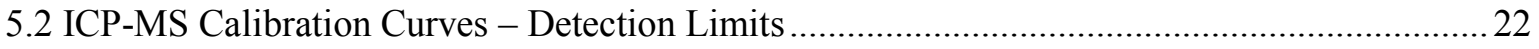

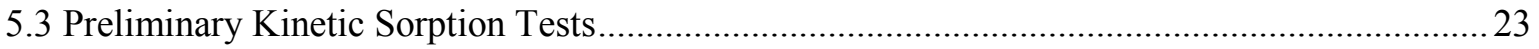

5.4 Sample Preparation - Baseline Batch Sorption Experiments ...............................................24

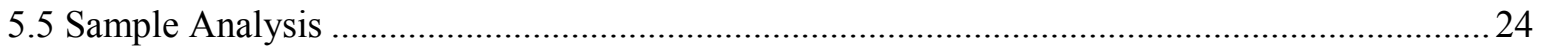

6.0 Appendix B: Materials and Methods for the Strontium Lysimeter Field Study...........................26

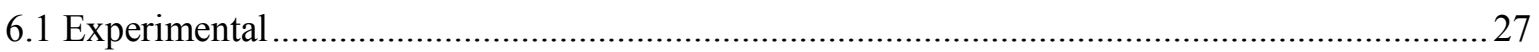

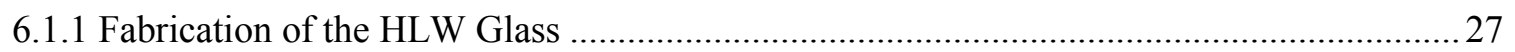

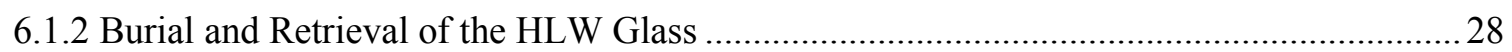

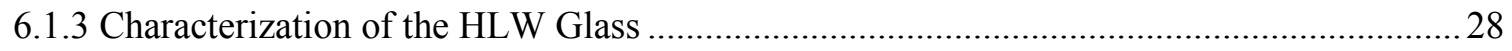




\section{LIST OF TABLES}

Table 1. Modeled reactions of neptunium with iron oxides. Reactions $5-7$ were omitted from the model due to their low probability of existing in the $\mathrm{pH}$ range of interest (Dzombak and Morel, 1990; Nakayama and Sakamoto, 1991; Turner, 1995)

Table 2. Clayey sediment surficial iron concentrations determined via the model for each combination of reactions used. Products represent reactions 3, 4, and 8 in Table 1. A " 1 " in the column under each reaction product indicates that it was included in the model. A " 0 " indicates that it was left out of the model. WSOS/DF (weighted sum of squares, of residuals divided by the degree of freedom represents the goodness of fit), where a lower value is a better fit to the data.

Table 3. Sandy sediment surficial iron concentrations determined via the model for each combination of reactions used. Products represent reactions 3, 4, and 8 in Table 1. A " 1 " in the column under each reaction product indicates that it was included in the model. A " 0 " indicates that it was left out of the model. WSOS/DF represents the goodness of fit, where a lower value is a better fit to the data.

Table 4. Sr K $\mathrm{d}_{\mathrm{d}}$ values for SRS clayey and sandy sediments. All values have units of $\mathrm{L} \mathrm{kg}^{-1} \ldots \ldots \ldots . . . .13$

Table 5. Descriptions of SRS sediments used in this work (Powell et al., 2002)..............................22

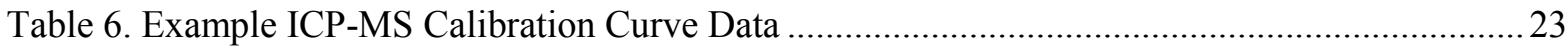




\section{LIST OF FIGURES}

Figure 1. Schematic of the lysimeter used in field study. Sr source consisted of a simulated highlevel waste glass pellet $(1.3 \mathrm{~cm}$ diameter x $1.3 \mathrm{~cm}$ length). Lysimeter was left exposed to natural SRS conditions for 11 years.

Figure 2. Burial glass fragment exhumed after 24 years.

Figure 3. Initial modeling iterations for the clayey and sandy sediments. For each sediment, each of the iterations were nearly identical when viewed graphically so only one line is used.

Figure 4: Model fit to data using all three reactions (Table 1, reactions 2, 3, and 8). The solid line represents the total amount of neptunium sorbed to the SRS lysimeter sediment while the dashed lines represent the fraction attributed to each of the different reactions.

Figure 5: Actual concentration data from the strontium lysimeter, $\mathrm{C}_{\mathrm{o}}$ is the concentration of the source term $(7.6 \mathrm{e} 9 \mathrm{dpm} / \mathrm{g})$ and $\mathrm{C}$ is the concentration of the sediment $(1461$ to $190 \mathrm{dpm} / \mathrm{g}) \ldots \ldots \ldots \ldots \ldots \ldots . . . .10$

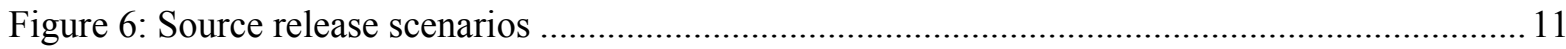

Figure 7: Rainfall (Gray) and Leachate (Black) Data for the M-2 Lysimeter................................... 12

Figure 8: Baseline model. "Model 1991" includes 11 years of transport modeling, whereas "Model 24 Years" includes 11 years of "Model 1991" plus an additional 13 years of diffusion to account for the time the lysimeter core remained in storage prior to ${ }^{90} \mathrm{Sr}$ sediment analysis.................... 14

Figure 9: Model with varying seepage velocity (units in $\mathrm{cm} \mathrm{hr}^{-1}$ )............................................... 15

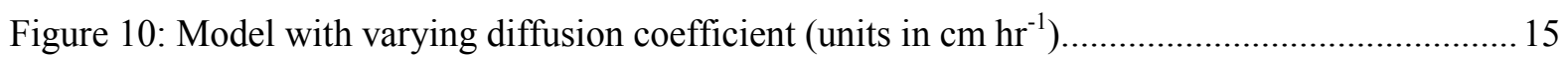

Figure 11: Model with varying $\mathrm{K}_{\mathrm{d}}$ values (units $\mathrm{L} \mathrm{kg}^{-1}$ ). While $32 \mathrm{~L} \mathrm{~kg}^{-1}$ is the best fit overall, the $\mathrm{K}_{\mathrm{d}}$ construct does not appear to be the only process influencing strontium interaction with the sediment.

Figure 12. Screen capture of a typical ${ }^{237} \mathrm{~Np}$ calibration curve using Thermo PlasmaLab software to control the data collection and analysis. $\mathrm{R}^{2}=0.999993$, Intercept Conc. (Detection Limit) $=$ $0.000018 \mathrm{ppb}$. 


\section{LIST OF ABBREVIATIONS}

CDB Citrate-Bicarbonate-Dithionite

DOE Department of Energy

DWPF Defense Waste Processing Facility

ICP-MS Inductively coupled plasma - mass spectrometer

$\mathrm{K}_{\mathrm{d}} \quad$ Distribution coefficient

$\mathrm{K}_{\mathrm{sp}} \quad$ Solubility value

LLW Low Level Waste

NOM Natural organic matter

PA Performance Assessment

SRNL Savannah River National Laboratory

SRS Savannah River Site

WSOS/DF Weighted sum of squares of residuals divided by the degree of freedom 


\subsection{Introduction}

The performance assessments (PA) used on the Savannah River Site (SRS) presently account for the interaction between radionuclides and subsurface solids through the use of solubility terms or more commonly with the distribution coefficients $\left(\mathrm{K}_{\mathrm{d}}\right.$ values). Solubility is generally described as the radionuclide concentration in the aqueous phase in the presence of an excess of radionuclide as a precipitated solid phase (units: $\mathrm{pCi} / \mathrm{L}$ ), whereas the $\mathrm{K}_{\mathrm{d}}$ is defined as the concentration ratio of the solid to aqueous phases (units $=(\mathrm{pCi} / \mathrm{g}) /(\mathrm{pCi} / \mathrm{mL})=\mathrm{mL} / \mathrm{g})$. These parameters have two important attributes in that they are readily assessable from the literature and they are relatively easily measured.

However, there have been a number of shortcomings associated with the $\mathrm{K}_{\mathrm{d}}$ construct, with which most contaminant transport modelers and geochemist users are readily knowledgeable (Bethke and Brady, 2000; Krupka et al., 1999). $\mathrm{K}_{\mathrm{d}}$ values are especially difficult to incorporate in predictive reactive transport modeling in geological transition zones, such as where formations are changing or where engineered barriers are being used, or at chemical speciation transition zones, such as where $\mathrm{pH}$ may be changing quickly. An example of the latter exists for $\mathrm{U} \mathrm{K}_{\mathrm{d}}$ values in SRS subsurface sandy sediments: at $\mathrm{pH} 4.55$ the $\mathrm{K}_{\mathrm{d}}$ value is $40 \mathrm{~mL} / \mathrm{g}$ and at $\mathrm{pH} 5.5$ the $\mathrm{U} \mathrm{K}_{\mathrm{d}}$ value is $\sim 10,000 \mathrm{~mL} / \mathrm{g}$ (Seaman and Kaplan, 2010; Serkiz and Johnson, 1994). Between these two $\mathrm{pH}$ values there were $30 \mathrm{~K}_{\mathrm{d}}$ measurements demonstrating a very steep steady $\mathrm{K}_{\mathrm{d}}$ increase, indicating the need for a strong tie between $\mathrm{pH}$ and $\mathrm{U} \mathrm{K}_{\mathrm{d}}$ should a $\mathrm{pH}-\mathrm{U}$ plume (e.g., cementitious leachate plume) move through a given sediment modeling node.

It is expected that the $\mathrm{K}_{\mathrm{d}}$ construct will be appropriate to use for a majority of the PA and for a majority of the radionuclides. However, semi-mechanistic models will be more representative in isolated cases where the chemistry is especially transitory or the radionuclide chemistry is especially complex, bringing to bear multiple species of varying sorption tendencies to the

sediment. Semi-mechanistic models explicitly accommodate the dependency of $\mathrm{K}_{d}$ values, or other sorption parameters, on contaminant concentration, competing ion concentrations, $\mathrm{pH}-$ dependent surface charge on the adsorbent, and solute species distribution. Incorporating semimechanistic concepts into geochemical models is desirable to make the models more robust and, perhaps more importantly from the standpoint of the PA, scientifically defensible. Alternatively, the $\mathrm{K}_{\mathrm{d}}$ model would not be appropriate when the chemistry is expected to change as a function of time.

There are several semi-mechanistic models that can describe solute adsorption; some are accurate only under limited environmental conditions (Sposito, 1984). For instance, the Stern model is a better model for describing adsorption of inner-sphere complexes, whereas the GouyChapman model is a better model for describing outer-sphere or diffuse-swarm adsorption (Sposito, 1984; Westall, 1986). References to excellent review articles have been included in the discussion to provide the interested reader with additional information. A brief description of the state of the science is presented below.

Experimental data on interactions at the mineral-electrolyte interface can be represented mathematically through two different approaches: 1) empirical models and 2) mechanistic models. An empirical model can be defined as a mathematical description of the experimental data without any particular theoretical basis. For example, the $\mathrm{K}_{\mathrm{d}}$, Freundlich isotherm, Langmuir isotherm, Langmuir Two-Surface Isotherm, and Competitive Langmuir are considered empirical models by this definition (Sposito, 1984). Mechanistic models refer to models based on 
thermodynamic concepts such as reactions described by mass action laws and material balance equations. Four of the most commonly used mechanistic models include the Helmholtz, GouyChapman, Stern, and Triple Layer models (Sposito, 1984). The empirical models are often mathematically simpler than mechanistic models and are suitable for characterizing sets of experimental data with a few adjustable parameters, or for interpolating between data points. On the other hand, mechanistic models contribute to an understanding of the chemistry at the interface and are often used for describing data from complex multi-component systems for which the mathematical formulation (i.e., functional relations) for an empirical model might not be obvious. Mechanistic models can also be used for interpolation and characterization of data sets in terms of a few adjustable parameters. However, mechanistic models are often mathematically more complicated than empirical relationships. Adjustable parameters are required for both mechanistic and empirical models, but not for the $\mathrm{K}_{\mathrm{d}}$ model.

Several mechanistic models have been proposed; however, their application to complex natural sediments is not resolved (Schindler and Sposito, 1991; Sposito, 1984; Westall, 1986; Westall and Hohl, 1980). Any complete mechanistic description of chemical reactions at the mineral-electrolyte interface must include a description of the electrical double layer. While this fact has been recognized for years, a satisfactory description of the double layer at the mineralelectrolyte interface still does not exist.

Part of the difficulty of characterizing this interface stems from the fact that natural mineral surfaces are very irregular and non-homogeneous. They consist of many different microcrystalline structures that exhibit quite different chemical properties when exposed to solutions. Thus, examination of the surface by virtually any experimental method yields only averaged characteristics of the surface and the interface. Parson (1982) discussed the surface chemistry of single crystals of pure metals and showed that the potential of zero charge of different crystal faces of the same pure metal can differ by over $400 \mathrm{mV}$. For an oxide surface, this difference was calculated to be energetically equivalent to a variation in the zero-point-of-charge of more than six pH units (Westall, 1986). This example indicated that an observable microscopic property of a polycrystalline surface might be the result of a combination of widely different microscopic properties and characterization of these surfaces will remain somewhat operational in nature.

Another fundamental problem encountered in characterizing reactions at the mineralelectrolyte interface is the coupling between electrostatic and chemical interactions, which makes it difficult to distinguish between their effects (Westall and Hohl, 1980). The inability of models to distinguish between electrostatic and chemical interaction at the mineral electrolyte interface has been well documented (Westall and Hohl, 1980).

Mechanistic or surface-complexation models were originally designed to describe welldefined systems of little or no heterogeneity, a far cry from natural sediments. One method of addressing heterogeneous systems is an empirical approach referred to as the generalized composite approach (Davis et al., 1998). In this approach experimental data on site sediments are fitted to various stoichiometric sorption reactions and model formulations based on reaction scheme simplicity and goodness-of-fit (Davis et al., 2004). This avoids the necessity of detailed mineralogical characterization required in the more common surface complexation approaches using "component additivity" (Davis et al., 1998). It is also important to note that the authors of this approach do not assign specific binding sites (e.g., Fe-oxide "B" sites or planar kaolinite sites) to the solid phases. 
Data collection to support the generalized composite approach requires experimental determination of surface complexation under all mineralogical and chemical conditions expected within a plume. The resulting data permits calculating semi-empirical geochemical sorption parameters that can then be used to describe contaminant sorption for a wide range of environmental conditions at the study site. Less site-specific data is required to support the component additivity approach and this approach can simulate changing conditions more realistically than the generalized composite approach. For example, if a phase is predicted to precipitate (or disappear) in the future it cannot be accounted for in the generalized composite approach, whereas this can be incorporated into the component additivity approach. The inclusion of these geochemical models into the PA or to validate $K_{d}$ values already being used in the PA is an eventual goal and studies are presently underway to accomplish this goal (Kaplan et al., 2010). One recent successful application of this modeling approach has been with Eu (an analogue for trivalent radionuclides), natural organic matter (an analogue for cellulosic degradation products), and SRS sediment (Kaplan et al., 2010). The value this brings is that a wide range of environmental conditions, in this case, sediment type, $\mathrm{pH}$, and natural organic matter concentrations, can be modeled, for a far more robust description than a Eu $\mathrm{K}_{\mathrm{d}}$ construct.

\subsection{Experimental Objectives}

Two modeling studies in this work were conducted based on data sets from previous studies funded by Solid Waste (Powell, 2010). The first was to model Np sorption to SRS sediment as a function of $\mathrm{pH}$ and as a function of $\mathrm{Np}$ concentration. When these studies were conducted, there was a need to quantify how $\mathrm{Np}$ sorbed to slit trench sediments as a function of $\mathrm{pH}$. The second was to model Sr sorption from an 11-yr field lysimeter study on the SRS. The value of a $\mathrm{Sr}$ sorption constant coming from this field study would be to validate the $\mathrm{K}_{\mathrm{d}}$ value obtained from the usual one-week batch experiment.

The objectives of this study were to:

1. Develop a quantitative thermodynamically-based model for neptunium sorption to SRS sediments.

2. Determine a Sr sorption constant from a SRS 11-year lysimeter study and conduct sensitivity analyses of various hydrological and chemical parameters. 
SRNL-STI-2012-00052

Revision 0

\subsection{Experimental Procedure}

\subsection{Neptunium Sorption as a Function of $\mathrm{pH}$}

The details of the batch Np sorption experiments were described previously (Powell, 2010), and are repeated in Appendix A. The data from these studies are modeled in this report. Briefly, SRS sandy or clayey sediments were used in batch sorption experiments. The sediment properties are presented in Table 5. Samples were prepared in $15 \mathrm{~mL}$ BD Falcon polypropylene centrifuge tubes. Each tube was first filled with the appropriate mass of sediment, filled with approximately $6 \mathrm{~mL}$ of distilled deionized water $\mathrm{H}_{2} \mathrm{O}$ and $1 \mathrm{~mL}$ of $0.1 \mathrm{M} \mathrm{NaCl}$ and the $\mathrm{pH}$ was adjusted as needed with $0.1 \mathrm{~N}$ and $0.01 \mathrm{~N} \mathrm{NaOH}$ and $\mathrm{HCl}$. All additions were individually measured gravimetrically, but generally contained approximately $1.00 \mathrm{~g}$ sediment and $12 \mathrm{~mL}$ aqueous phase. The sediment suspension was then mixed end-over-end at eight rpm for one week to equilibrate with the solution. There were two sets of studies. In one, the $\mathrm{Np}$ concentration was varied between 0.1 to $100 \mathrm{ppb}$ (three orders of magnitude) in the sediment suspension. The second involved varying the $\mathrm{pH}$ between 4.5 and 8.0 .

\subsection{Field Lysimeter Sr Study}

A radiological field lysimeter program was established at SRS in the early 1980s. Among the 136 lysimeters was one in which the tendency for radionuclides to leach from SRS glass was tested(Jantzen et al., 2008). A detailed description of the lysimeter and preparation of the glass source term is presented in Appendix B. For this test, a $50 \mathrm{~L}$ carboy was inverted, its bottom removed, and it was filled with SRS vadose sediment (Figure 1). A $1.3 \mathrm{~cm}$ diameter $\mathrm{x} 1.3 \mathrm{~cm}$ length glass pellet simulating Defense Waste Processing Facility (DWPF) vitrified waste was placed $22 \mathrm{~cm}$ below the ground surface (Figure 2).

This pellet contained Tank 15 aqueous waste, including $31.68 \mathrm{mCi}{ }^{90} \mathrm{Sr}$. After 11 years, a 7.6-cm diameter core was recovered from the lysimeter. It was sectioned into $1.25 \mathrm{~cm}$ thick section down the $60 \mathrm{~cm}$ length core. Total sediment ${ }^{90} \mathrm{Sr}$ concentrations of each section were determined. Numerical modeling of the sediment ${ }^{90} \mathrm{Sr}$ concentrations was conducted to estimate the extent of ${ }^{90} \mathrm{Sr}$ sorption; $\mathrm{K}_{\mathrm{d}}$ values were ultimately calculated from these data. Additional information about the lysimeter program, including the rainfall, leachate collection program, and the ${ }^{90} \mathrm{Sr}$ sediment concentrations are presented in Section 3.2. A description of the model is presented in Section 3.2.2. 
SRNL-STI-2012-00052

Revision 0

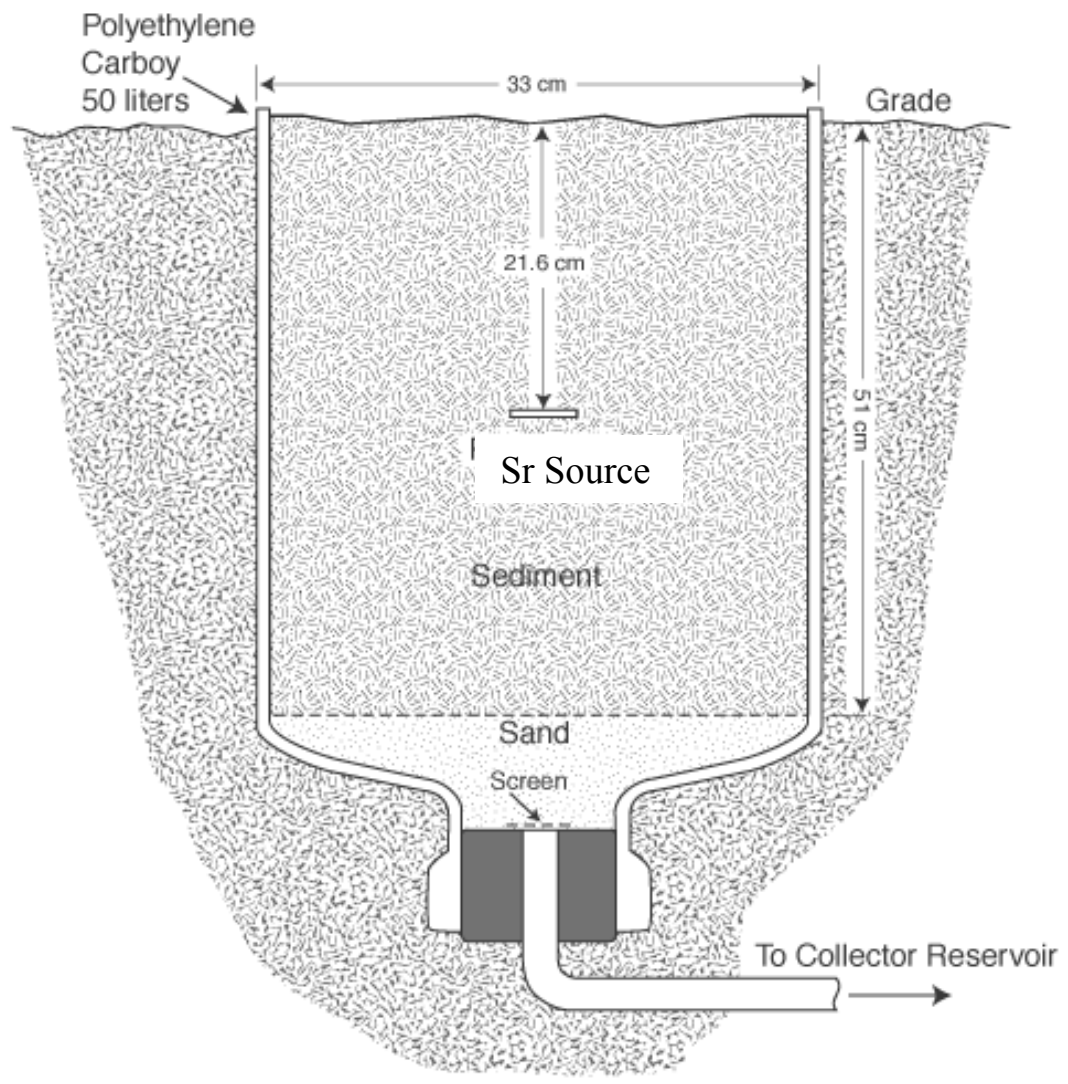

Figure 1. Schematic of the lysimeter used in field study. Sr source consisted of a simulated high-level waste glass pellet $(1.3 \mathrm{~cm}$ diameter x $1.3 \mathrm{~cm}$ length). Lysimeter was left exposed to natural SRS conditions for 11 years.

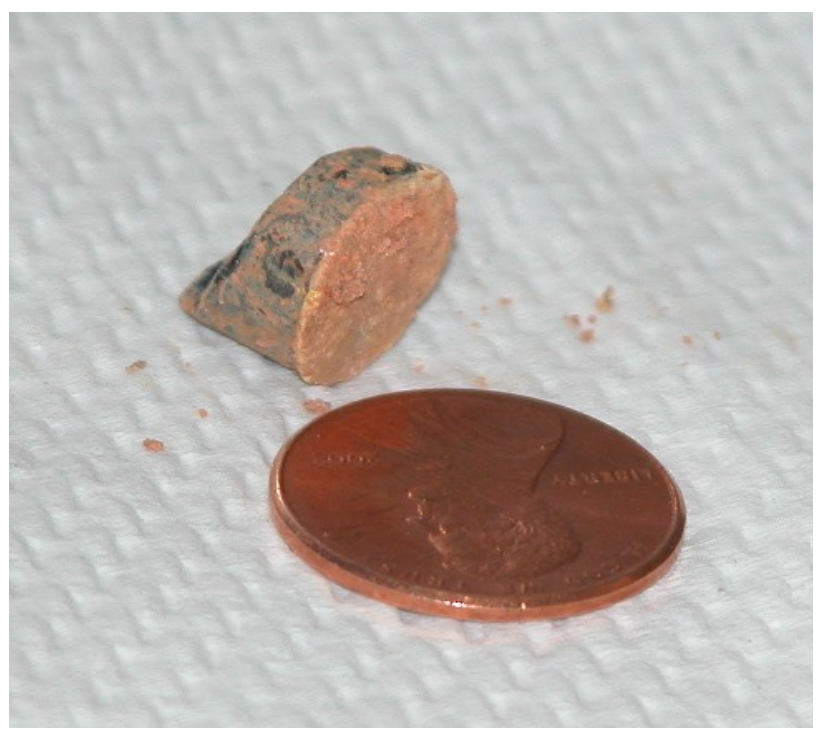

Figure 2. Burial glass fragment exhumed after 24 years. 
SRNL-STI-2012-00052

Revision 0

\subsection{Results and Discussion}

\subsection{Modeling Neptunium Sorption}

Based on previous batch sorption observations (Girvin et al., 1990) and X-ray absorption spectroscopy observations (Arai et al., 2007) on other minerals and sediments, it was assumed that neptunium interactions with iron surface sites will be the dominant sorption reaction on SRS sediments. Girvin et al. (Girvin et al., 1990) gave a generalized equation for neptunium(V) sorption to surficial iron as $\equiv \mathrm{FeOH}+\mathrm{NpO}_{2}{ }^{+} \rightarrow \equiv \mathrm{FeONpO}_{2}+\mathrm{H}^{+}$. More detailed sorption equations are shown in Table 1. Surface species $\equiv \mathrm{FeONpO}_{2} \mathrm{OH}^{-}, \equiv \mathrm{FeOHNpO} \mathrm{O}_{2} \mathrm{OH}$, and $\equiv \mathrm{FeOH}_{2} \mathrm{NpO}_{2} \mathrm{OH}^{+}$were assumed to be negligible in the $\mathrm{pH}$ range of interest due to the low likelihood of $\mathrm{NpO}_{2}{ }^{+}$hydrolysis and were not incorporated into the model. The bidentate, inner sphere bis-carbonato complex $\left((\equiv \mathrm{FeO})_{2} \mathrm{NpO}_{2}\left(\mathrm{CO}_{3}\right)_{2}{ }^{-5}\right)$ has been shown spectroscopically (Arai et al., 2007). However, this surface complex generally forms at high $\mathrm{pH}$ systems and is limited to systems with relatively high dissolved carbonate concentrations. Therefore, it is not applicable in the low $\mathrm{pH}$ of the baseline sorption isotherms generated as part of this work.

Table 1. Modeled reactions of neptunium with iron oxides. Reactions $5-7$ were omitted from the model due to their low probability of existing in the $\mathrm{pH}$ range of interest (Dzombak and Morel, 1990; Nakayama and Sakamoto, 1991; Turner, 1995).

\begin{tabular}{|l|l|l|}
\multicolumn{2}{l|}{ Reaction } & \multicolumn{2}{l|}{ Log } \\
\hline 1 & $\equiv \mathrm{FeOH}+\mathrm{H}^{+} \rightarrow \equiv \mathrm{FeOH}_{2}$ & -9.17 \\
\hline 2 & $\equiv \mathrm{FeOH} \rightarrow \equiv \mathrm{FeO}^{-}+\mathrm{H}^{+}$ & -2.54 \\
\hline 3 & $\equiv \mathrm{FeOH}+\mathrm{NpO}_{2}^{+} \rightarrow \equiv \mathrm{FeONpO}_{2}+\mathrm{H}^{+}$ & 5.21 \\
\hline 4 & $\equiv \mathrm{FeOH}+\mathrm{NpO}_{2}^{+} \rightarrow \equiv \mathrm{FeOHNpO}_{2}^{+}$ & -10.39 \\
\hline 5 & $\equiv \mathrm{FeOH}+\mathrm{NpO}_{2}^{+}+\mathrm{H}_{2} \mathrm{O} \rightarrow \equiv \mathrm{FeONpO}_{2} \mathrm{OH}^{-}+2 \mathrm{H}^{+}$ & -2.54 \\
\hline 6 & $\equiv \mathrm{FeOH}+\mathrm{NpO}_{2}^{+}+\mathrm{H}_{2} \mathrm{O} \rightarrow \equiv \mathrm{FeOHNpO}_{2} \mathrm{OH}+\mathrm{H}^{+}$ & 5.21 \\
\hline 7 & $\equiv \mathrm{FeOH}{ }^{+}+\mathrm{NpO}_{2}^{+}+\mathrm{H}_{2} \mathrm{O} \rightarrow \equiv \mathrm{FeOH}_{2} \mathrm{NpO}_{2} \mathrm{OH}^{+}+\mathrm{H}^{+}$ & -5.96 \\
\hline 8 & $\equiv 2 \mathrm{FeOH}+\mathrm{NpO}_{2}^{+} \rightarrow \equiv(\mathrm{FeO})_{2} \mathrm{NpO}_{2}{ }^{-}+2 \mathrm{H}^{+}$ & \\
\hline
\end{tabular}

The data were modeled using a diffuse-double layer model within FITEQL. This model was chosen based on simplicity and the lowest number of required data fitting parameters. The data from the baseline sorption experiments including total neptunium concentration, sorbed neptunium concentration, and $\mathrm{pH}$ were used as inputs into the model in order to solve for the concentration of available iron. The modeling was conducted using each reaction independently and then using each possible combination of the above reactions (Figure 3 ).

For the clayey sediment (Table 2), the surficial iron concentration was determined to be 2.40E-04 M $\pm 1.52 \mathrm{E}-04$ and the sandy sediment (Table 3) surficial iron concentration was 1.30E$4 \mathrm{M} \pm 1.12 \mathrm{E}-04$. These numbers were compared against measured Citrate-Bicarbonate-Dithionite 
(CDB) extractable iron concentrations (which are approximately representative of the concentrations of crystalline and non-crystalline iron oxides in the sediment) for the two sediments to determine the amount of $\mathrm{CDB}$ iron that was involved in the sorption process. For the clayey sediment, the CDB iron concentration was $6.83 \mathrm{E}-03 \mathrm{M}$. This was calculated by multiplying the sediment concentration by the $\mathrm{CDB}$ iron concentration and dividing by the molecular weight of iron. This resulted in roughly $3.51 \%(1.28-5.74 \%)$ of the total CDB iron being involved in sorption. For the sandy sediment, the CDB iron concentration was $3.16 \mathrm{E}-03 \mathrm{M}$, which indicated that $4.11 \%(0.57-7.66 \%)$ of the CDB iron was involved in sorption. Using these data (and equations 3, 4, and 8 from Table 1), it was possible to estimate sorption behavior of neptunium onto sediments by knowing their $\mathrm{CDB}$ iron concentration and assuming that $3-5 \%$ of that is available for sorption.

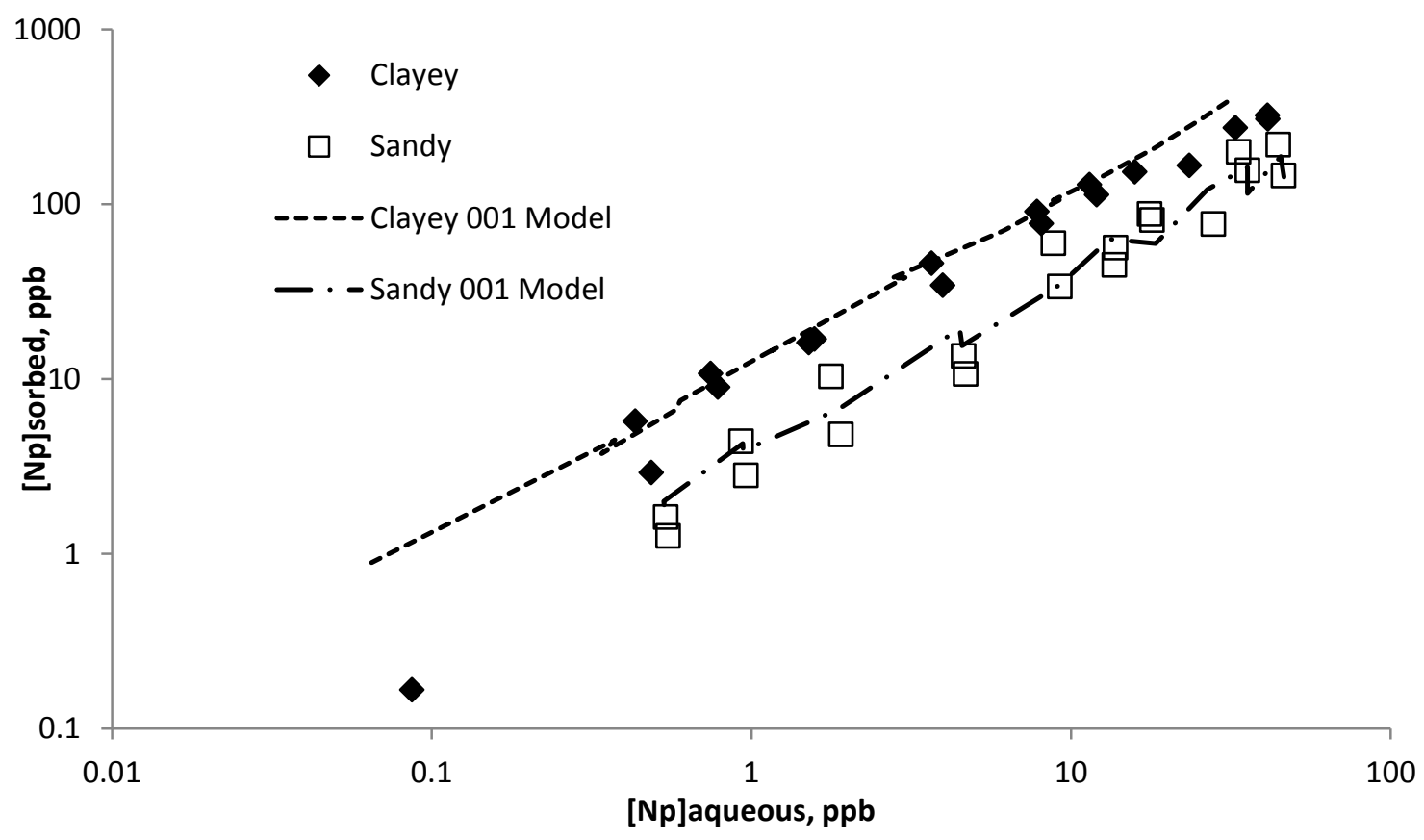

Figure 3. Initial modeling iterations for the clayey and sandy sediments. For each sediment, each of the iterations were nearly identical when viewed graphically so only one line is used. 
Table 2. Clayey sediment surficial iron concentrations determined via the model for each combination of reactions used. Products represent reactions 3, 4, and 8 in Table 1. A "1" in the column under each reaction product indicates that it was included in the model. A " 0 " indicates that it was left out of the model. WSOS/DF (weighted sum of squares, of residuals divided by the degree of freedom represents the goodness of fit), where a lower value is a better fit to the data.

\begin{tabular}{|c|c|c|l|l|}
\hline$\equiv \mathrm{FeONpO}_{2}$ & $\equiv \mathrm{FeOHNpO}_{2}{ }^{+}$ & $\equiv(\mathrm{FeO})_{2} \mathrm{NpO}_{2}^{-}$ & {$[\equiv \mathrm{FeOH}]$} & WSOS/DF \\
\hline 1 & 0 & 0 & $5.51 \mathrm{E}-04$ & 16.33 \\
\hline 1 & 1 & 0 & $1.52 \mathrm{E}-04$ & 18.98 \\
\hline 1 & 0 & 1 & $3.25 \mathrm{E}-04$ & 12.14 \\
\hline 1 & 1 & 1 & $1.49 \mathrm{E}-04$ & 18.67 \\
\hline 0 & 1 & 0 & $1.89 \mathrm{E}-04$ & 20.1 \\
\hline 0 & 0 & 1 & $3.82 \mathrm{E}-04$ & 10.47 \\
\hline 0 & 1 & 1 & $1.77 \mathrm{E}-04$ & 19.36 \\
\hline
\end{tabular}

Average $2.40 \mathrm{E}-04$

Table 3. Sandy sediment surficial iron concentrations determined via the model for each combination of reactions used. Products represent reactions 3,4 , and 8 in Table 1. A " 1 " in the column under each reaction product indicates that it was included in the model. A "0" indicates that it was left out of the model. WSOS/DF represents the goodness of fit, where a lower value is a better fit to the data.

Reactions
\begin{tabular}{|c|c|c|c|c|}
\hline$\equiv \mathrm{FeONpO}_{2}$ & $\equiv \mathrm{FeOHNpO}_{2}{ }^{+}$ & $\equiv(\mathrm{FeO})_{2} \mathrm{NpO}_{2}{ }^{-}$ & {$[\equiv \mathrm{FeOH}]$} & WSOS/DF \\
\hline 1 & 0 & 0 & $2.49 \mathrm{E}-04$ & 11.82 \\
\hline 1 & 1 & 0 & $4.10 \mathrm{E}-05$ & 13.44 \\
\hline 1 & 0 & 1 & $2.08 \mathrm{E}-04$ & 10.64 \\
\hline 1 & 1 & 1 & $4.10 \mathrm{E}-05$ & 13.44 \\
\hline 0 & 1 & 0 & $4.22 \mathrm{E}-05$ & 13.56 \\
\hline 0 & 0 & 1 & $2.85 \mathrm{E}-04$ & 8.947 \\
\hline 0 & 1 & 1 & $4.22 \mathrm{E}-05$ & 13.56 \\
\hline
\end{tabular}

This idea was evaluated by trying to blindly fit sorption data obtained by a colleague using an SRS lysimeter sediment that differed from the end member sediments used in previous experiments (Amy Hixon, Clemson University, unpublished results, 2011). This sediment had a CDB iron concentration of $1.21 \mathrm{E}-03 \mathrm{M}$ which was less than that for either of the clayey or sandy sediments used before. An iron concentration of $4.52 \mathrm{E}-05 \mathrm{M}$ was used as an input to the model which represented $3.75 \%$ of the CDB iron concentration. This was the midpoint between the sandy and clayey sediment values determined earlier (Figure 4). The figure shows that the model does a good job at predicting the fraction of neptunium sorbed as a function of $\mathrm{pH}$. It is also 
shown that, as $\mathrm{pH}$ increases, the dominant sorption reaction moves from the $\mathrm{pH}$ independent $\equiv \mathrm{FeOHNpO}_{2}{ }^{+}$, to the first order $\mathrm{pH}$ dependent $\equiv \mathrm{FeONpO}_{2}$, and then to the second order $\mathrm{pH}$ dependent $(\equiv \mathrm{FeO})_{2} \mathrm{NpO}_{2}{ }^{-}$. This is consistent with the spectroscopically identified bidentate $\mathrm{Np}$ surface complexes at high $\mathrm{pH}$ (Arai et al., 2007).

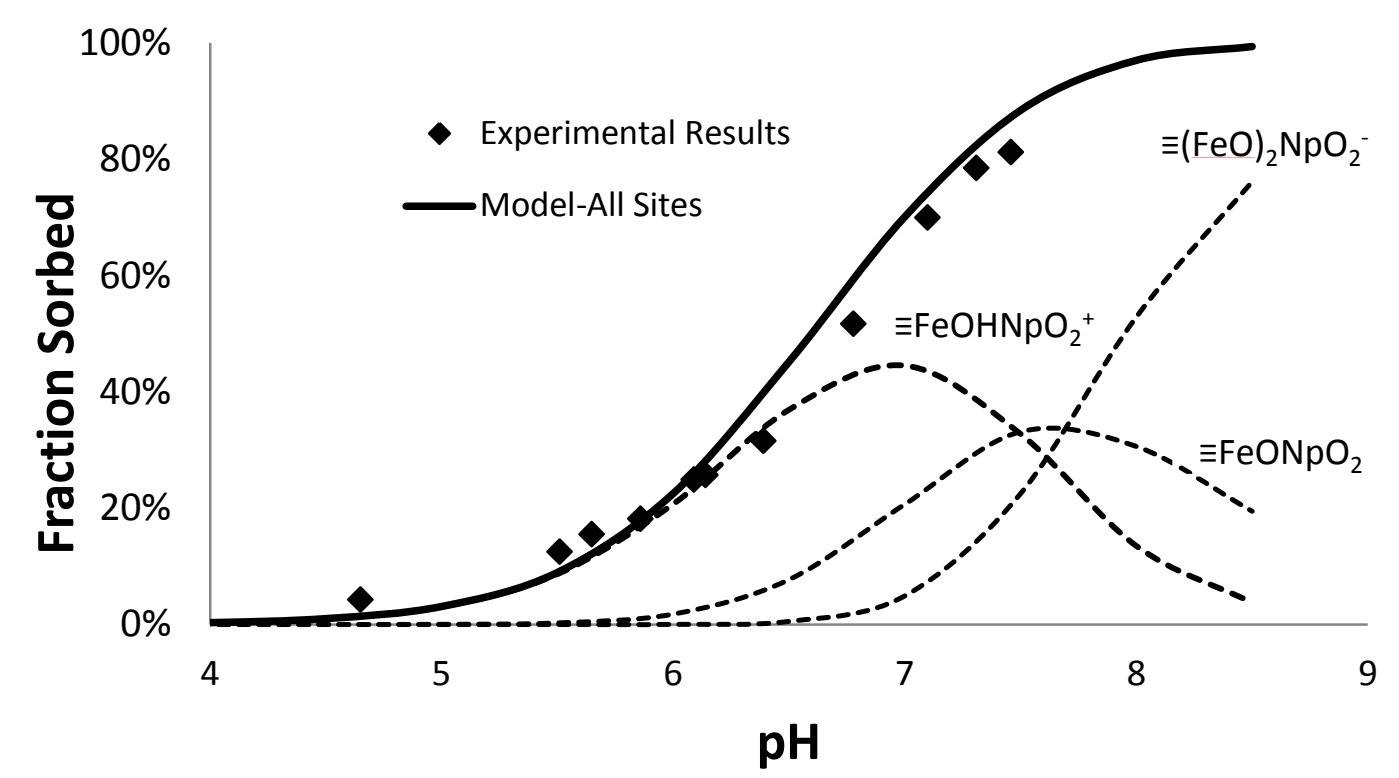

Figure 4: Model fit to data using all three reactions (Table 1, reactions 2, 3, and 8). The solid line represents the total amount of neptunium sorbed to the SRS lysimeter sediment while the dashed lines represent the fraction attributed to each of the different reactions.

Figure 4 indicates that there was an acceptable fit to the experimental data. Furthermore, the modeling results suggest that the assumptions underlying the model may be reasonable. One of the primary assumptions was that $\mathrm{Np}$ existed exclusively as $\mathrm{NpO}_{2}{ }^{+}$and that essentially no reduced $\mathrm{Np}$ (IV) was present in the SRS sediments (Powell, 2010). This was based on several experiments in Powell et al. ${ }^{17}$ Another important assumption was that the $\mathrm{NpO}_{2}{ }^{+}$sorbed exclusively to iron oxides that could be measured by Citrate-Bicarbonate-Dithionite (CDB) extractions. Finally, the limited number of equations in Table 1 provide a robust description of $\mathrm{NpO}_{2}{ }^{+}$sorption to SRS sediments over a $\mathrm{pH}$ range of 4.5 to 8.0 and over a $\mathrm{NpO}_{2}^{+}$concentration of four-orders-ofmagnitude.

\subsection{Field Lysimeter Sr Studies}

\subsubsection{Lysimeter Objective and Overview}

The purpose of this work was to develop a simplistic model to predict strontium migration in the subsurface and to calculate sorption parameters, including $\mathrm{K}_{\mathrm{d}}$ values. This model was compared to laboratory sorption values derived from conventional batch sorption tests. As stated in Section 2.2, the strontium lysimeter waste form consisted of a $1.3 \mathrm{~cm}$ diameter by $1.3 \mathrm{~cm}$ long Defense Waste Processing Facility vitrified glass pellet buried containing $31.68 \mathrm{mCi}{ }^{90} \mathrm{Sr}$. This 
pellet was buried in a bottomless, inverted 50-L polyethylene carboy filled with vadose zone sediment.

The strontium lysimeter experiment began in May 1981. From May of 1981 until November of 1988, leachate from the bottom of the lysimeter was collected for analysis. The burial ground area witnessed heavy rainfalls which caused flooding in August of 1990 and the summer of 1991 which rendered the water collection apparatus inaccessible. The lysimeter was then capped to prevent further rainfall infiltration. In 1996, the lysimeter was cored and, in 2004, the coring was sampled. The resultant data is shown in Figure 5.

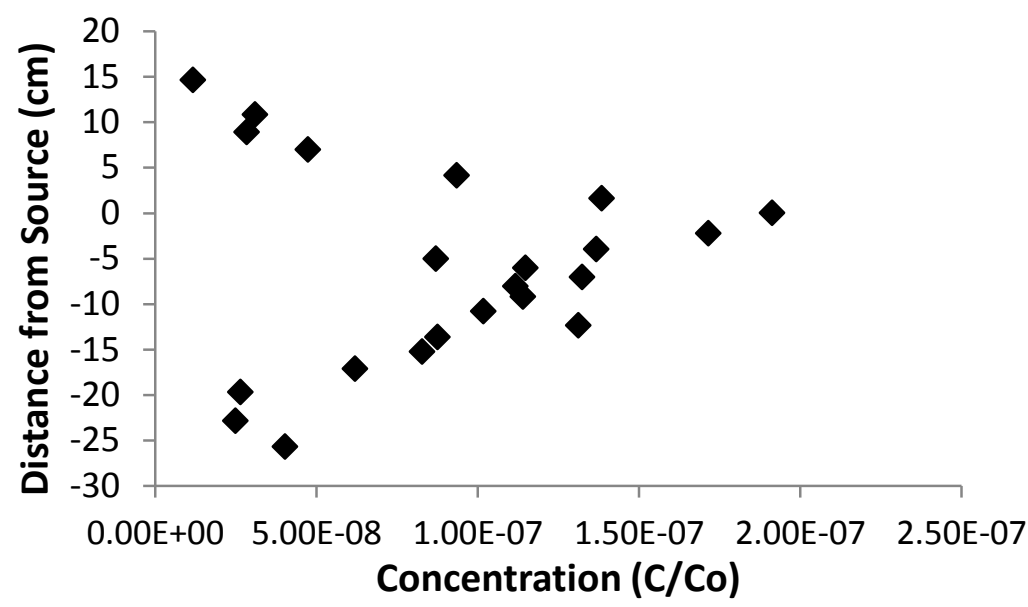

Figure 5: Actual concentration data from the strontium lysimeter, $C_{0}$ is the concentration of the source term $(7.6 \mathrm{e} 9 \mathrm{dpm} / \mathrm{g})$ and $\mathrm{C}$ is the concentration of the sediment (1461 to $190 \mathrm{dpm} / \mathrm{g}$ )

\subsubsection{Model Description}

Strontium migration in the lysimeter was modeled using a one dimensional flow assumption. The governing equation is shown in Equation 1. The fully implicit finite difference approximation of this governing equation is shown in Equation 2.

$$
\begin{gathered}
R \frac{\partial C_{S r}}{\partial t}=-v \frac{\partial C_{S r}}{\partial z}+D \frac{\partial^{2} C_{S r}}{\partial z^{2}} \\
C_{S r(i, j)}=\frac{-v \Delta t}{2 \Delta z R}\left[C_{S r(i+1, j-1)}-C_{S r(i-1, j)}\right]+\frac{D \Delta t}{R \Delta z^{2}}\left[C_{S r(i+1, j-1)}-2 C_{S r(i, j-1)}+C_{S r(i-1, j)}\right]+C_{S r(i, j-1)}
\end{gathered}
$$

Where: $\quad \mathrm{C}_{\mathrm{Sr}} \quad$ Strontium concentration (dimensionless)

$(\mathrm{i}, \mathrm{j}) \quad$ node $\mathrm{i}$ and time step $\mathrm{j}$

$\mathrm{v}$ Seepage velocity $\left(\mathrm{cm} \mathrm{hr}^{-1}\right)$

$\Delta \mathrm{t} \quad$ Time step (hr)

$\Delta \mathrm{z} \quad$ Size of node $(\mathrm{cm})$

$\mathrm{R} \quad$ Retardation factor (dimensionless)

D Dispersion coefficient $\left(\mathrm{cm}^{2} \mathrm{hr}^{-1}\right)$ 


\subsubsection{Strontium Source}

The strontium source was modeled by assuming that the node where the source is located has a constant concentration of 1.91E-07 (sediment concentration is expressed as $\mathrm{C} / \mathrm{C}_{\mathrm{o}}$, or normalized concentration: $\mathrm{C}=\mathrm{Sr}$ sediment concentration and $\mathrm{C}_{\mathrm{o}}$ is $\mathrm{Sr}$ concentration in the source term). The concentration represents the total (aqueous and sediment) strontium concentration. This assumption was used since the amount of strontium activity released during the 24 years of the experiment was extremely small relative to the total activity of the source pellet $(0.011 \%)$.

Two other release scenarios are also possible. The first is an increasing source concentration which assumes that the leach rate of strontium from the glass pellet is slow relative to the length of the experiment. The second scenario is a decreasing source concentration which assumes that the leach rate is fast and the pellet has become depleted of strontium. Figure 6 shows how these two release scenarios could be modeled.

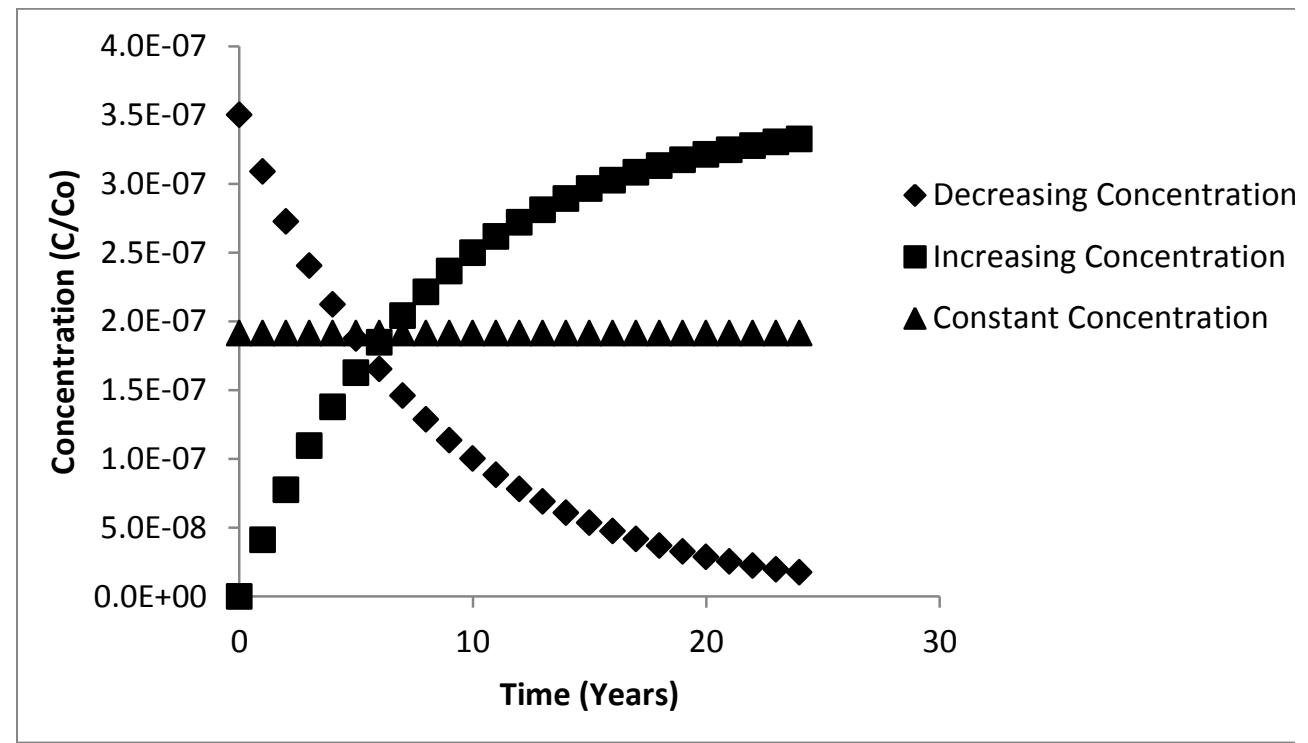

Figure 6: Source release scenarios

\subsubsection{Seepage Velocity}

Rainfall data was collected for the lysimeter monthly through the end of 1984 . From 1985 until the lysimeter was capped, no record of rainfall data is available. The leachate which flowed through the bottom of the lysimeter was also collected during this time period. A summary of these data is shown in Figure 7. 


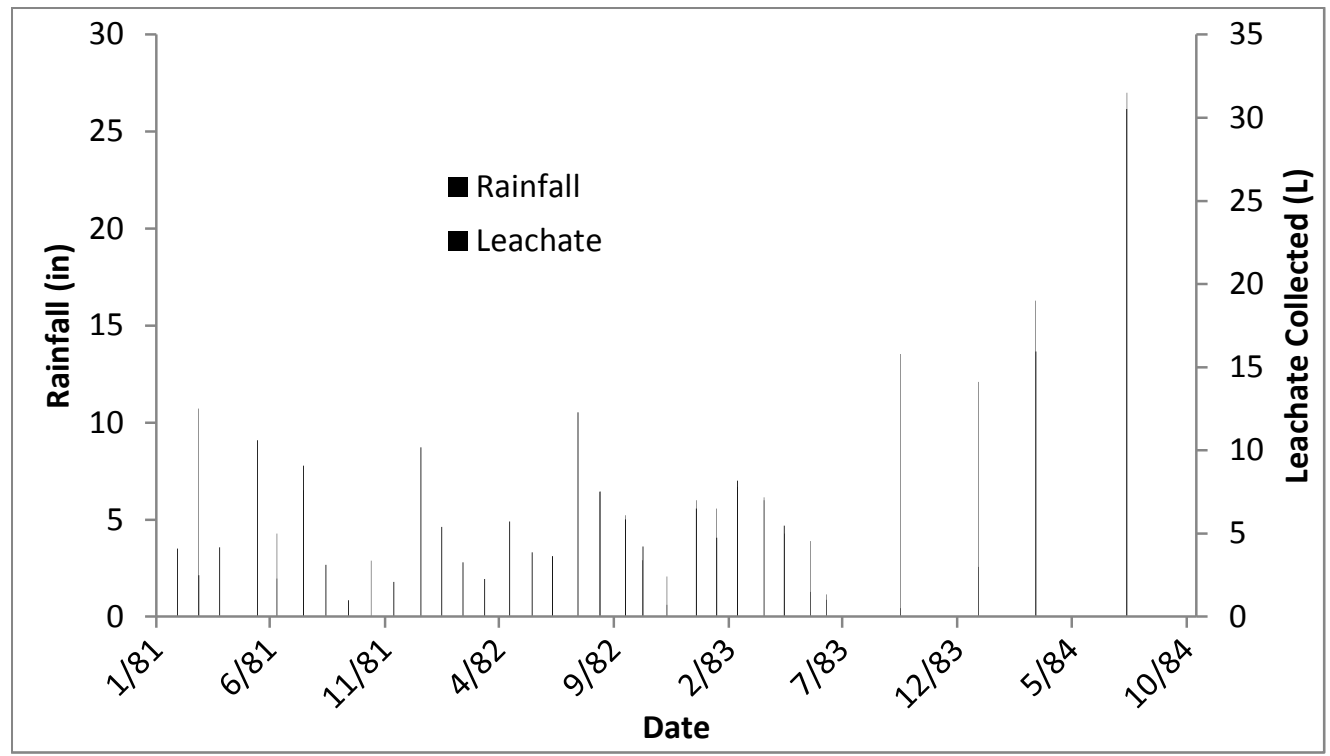

Figure 7: Rainfall (Gray) and Leachate (Black) Data for the M-2 Lysimeter.

First, a Darcy velocity was determined by taking the total volume of leachate collected and dividing by the surface area of the lysimeter $\left(\pi \mathrm{r}^{2}=\pi \cdot 16.5^{2}=855 \mathrm{~cm}^{2}\right)$ and the duration of the experiment. Two separate Darcy velocities were calculated for this data set because it seems that, during the first half of the data set, some leachate data is missing. The total volume of leachate collected $(136.7 \mathrm{~L})$ over a time period of 3.78 years resulted in a Darcy velocity of $4.16 \mathrm{~cm} \mathrm{~h}^{-1}$. Using the time period from 9/1/1982 until 11/1/1984, a total of $108 \mathrm{~L}$ of leachate was collected over a time period of 2.17 years which yielded a Darcy velocity of $5.72 \mathrm{~cm} \mathrm{~h}^{-1}$.

Seepage velocity is calculated by dividing the Darcy velocity by the average water content. The average water content $(\theta)$ for the lysimeter experiments was $0.25 .^{17}$ Using this value, seepage velocities for the entire data range and the truncated portion were $0.0167 \mathrm{~cm} \mathrm{hr}^{-1}$ and $0.0229 \mathrm{~cm} \mathrm{hr}^{-1}$, respectively.

\subsubsection{Retardation Factor}

The retardation factor is a measure of how fast a contaminant moves through the environment relative to the average water velocity. A retardation factor of unity represents a contaminant that moves at the same velocity as the groundwater while a contaminant with a retardation of 100 moves at $1 / 100$ the velocity of the groundwater. The retardation factor is calculated using the sediment/water partitioning coefficient, $K_{d}$ via Equation 3 (Freeze and Cherry, 1979).

$$
R=1+\frac{\rho K_{d}}{\theta}
$$

Where:

$\begin{array}{ll}\mathrm{R} & \text { Retardation factor }(\text { dimensionless }) \\ \rho & \text { Sediment density }\left(\mathrm{kg} \mathrm{m}^{3}\right) \\ \mathrm{K}_{\mathrm{d}} & \text { Sediment/water partitioning coefficient }\left(\mathrm{L} \mathrm{kg}^{-1}\right) \\ \theta & \text { Average water content (dimensionless) }\end{array}$


The $K_{d}$ values for strontium were determined in a prior experiment (Powell, 2010) using SRS sediments at similar $\mathrm{pH}$ values and ionic strength concentrations as existed in the lysimeters. The experiments were performed on a Subsurface Clayey and a Subsurface Sandy sediment at ionic strength concentrations of $0.02 \mathrm{~N}$ and $0.1 \mathrm{~N}$ and a $\mathrm{pH}$ of 5.5. The results from these experiments are shown in Table 4. The lysimeter sediment and aqueous chemistry most closely mirror the clayey sediment at the lower ionic strength concentration. Using this $K_{d}$ value of $32 \mathrm{~L} \mathrm{~kg}^{-1}$, the average water content $(\theta)$ for the lysimeter experiments of 0.25 (Demirkanli et al., 2008), and a bulk density $(\rho)$ of $1.6 \mathrm{~kg} \mathrm{~m}^{3}$ and Equation (3), a retardation factor of 200 (unitless) is obtained. We will discuss this value more in Section 3.2.7.

Table 4. Sr $\mathrm{K}_{\mathrm{d}}$ values for SRS clayey and sandy sediments. All values have units of $\mathrm{L} \mathrm{kg}^{-1}$.

\begin{tabular}{|c|c|c|c|}
\hline \multicolumn{2}{|c|}{ Clayey } & \multicolumn{2}{c|}{ Sandy } \\
\hline $0.02 \mathrm{~N}$ & $0.1 \mathrm{~N}$ & $0.02 \mathrm{~N}$ & $0.1 \mathrm{~N}$ \\
\hline $32.06 \pm 3.62$ & $8.05 \pm 0.62$ & $5.86 \pm 0.35$ & $6.02 \pm 0.14$ \\
\hline
\end{tabular}

\subsubsection{Dispersion Coefficient}

The dispersion coefficient, shown in Equation 4, is made up of two parts, advective dispersion and molecular diffusion. The advective term is the product of the dispersivity $\left(\alpha_{\mathrm{L}}\right)$ and the seepage velocity $(v)$. The dispersivity was determined to be $0.3 \mathrm{~cm}$ based on column experiments (Demirkanli et al., 2008). The molecular dispersion term is the product of the tortuosity $(\omega)$ and the molecular diffusion coefficient $\left(D_{d}\right)$. The tortuosity was determined to be 0.4 based on the mean particle size

$$
D_{L}=\alpha_{L} v+\omega D_{d}
$$

$\begin{array}{lll}\text { Where: } & \mathrm{D}_{\mathrm{L}} & \text { Dispersion coefficient }\left(\mathrm{cm} \mathrm{hr}^{-2}\right) \\ & \alpha_{\mathrm{L}} & \text { Dispersivity }(\mathrm{cm}) \\ v & \text { Seepage velocity }\left(\mathrm{cm} \mathrm{hr}^{-1}\right) \\ \omega & \text { Tortuosity (dimensionless) } \\ & \mathrm{D}_{\mathrm{d}} & \text { Molecular dispersion coefficient }\left(\mathrm{cm} \mathrm{hr}^{-2}\right)\end{array}$

Literature values for the dispersion coefficient for strontium range from 1.1E-04-2.3E-03 $\mathrm{cm} \mathrm{s}^{-2}$ (Sims et al., 2008). However, during an experiment designed to determine dispersion coefficients for strontium, Sims et al. ${ }^{23}$ showed that the calculated dispersion coefficients from their column experiments were greater than the unperturbed subsurface experiments. They obtained dispersion coefficients ranging from $0.029-0.068 \mathrm{~cm} \mathrm{hr}^{-2}$.

The advective portion of the dispersion coefficient $\left(\alpha_{\mathrm{L}} \mathrm{x} v\right)$ is roughly $5 \mathrm{E}-03-7 \mathrm{E}-03 \mathrm{~cm} \mathrm{hr}^{-2}$. This is on the order of the literature values but is an order of magnitude less than the experimentally determined values. Also, it is unclear whether or not the values reported in Sims et al. (2008) represent the molecular diffusion coefficient or the overall dispersion coefficient(Sims et al., 2008). A range of values was tested to see which values gave the best fit to the data.

\subsubsection{Model Testing}


The best model fit to the actual data was obtained using the following parameters:

- a constant source concentration of $1.91 \mathrm{E}-07\left(\mathrm{C} / \mathrm{C}_{\mathrm{o}}\right)$,

- seepage velocity of $0.0167 \mathrm{~cm} \mathrm{hr}^{-1}$,

- $\mathrm{K}_{\mathrm{d}}$ of 32 (retardation factor 199.4), and

- molecular dispersion coefficient of $0.0725 \mathrm{~cm}^{2} \mathrm{hr}^{-1}$ (see Section 3.2.5).

The baseline model is shown in Figure 8. The 1991 model shows the degree of strontium migration when the lysimeter was capped while the 24 year model highlights the additional migration due to diffusion after the core sample was collected in 1991 and stored in a cooler. Above the source term, there is some additional upward migration that may be attributed to diffusion, whereas below the source term $(0 \mathrm{~cm}$ distance from source, Figure 8$)$, there was negligible amount of additional movement attributable to diffusion.

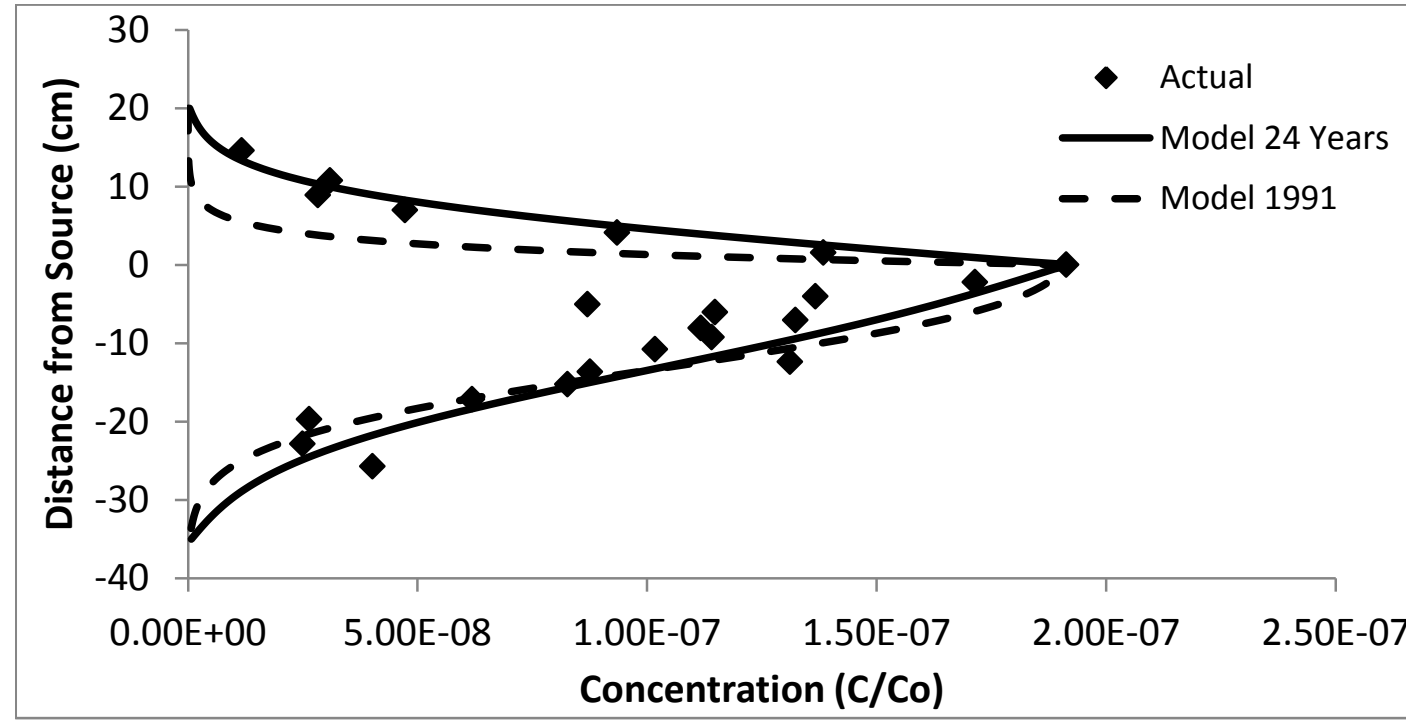

Figure 8: Baseline model. "Model 1991" includes 11 years of transport modeling, whereas "Model 24 Years" includes 11 years of "Model 1991" plus an additional 13 years of diffusion to account for the time the lysimeter core remained in storage prior to ${ }^{90} \mathrm{Sr}$ sediment analysis.

Figure 9 shows the effect of the changes in the seepage velocity (infiltration rate) on the accuracy of the model. The figure shows that changes in the seepage velocity have minimal effects on the upward movement of strontium. Conversely, the higher seepage velocities result in increased strontium movement downwards. 


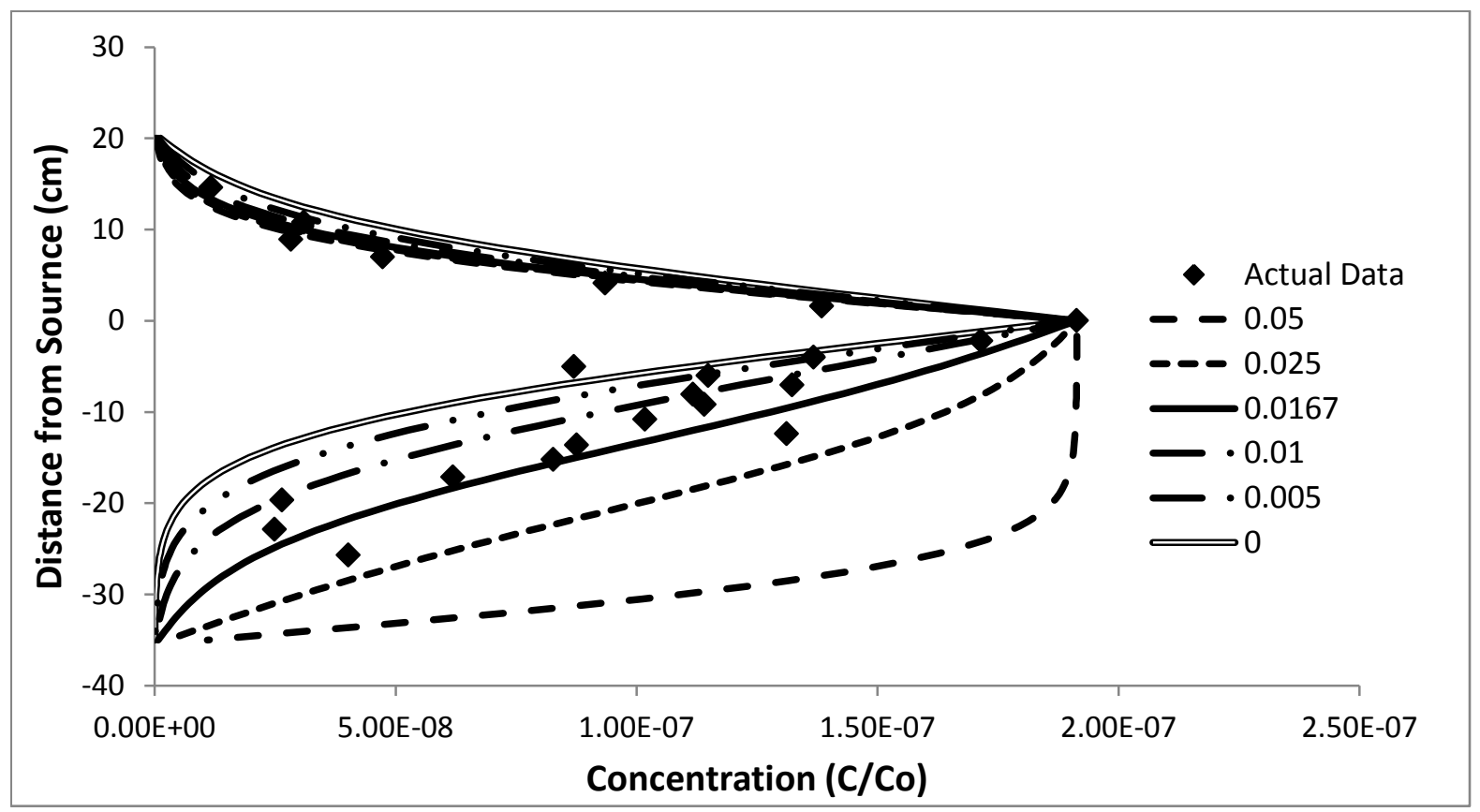

Figure 9: Model with varying seepage velocity (units in $\mathrm{cm} \mathrm{hr}^{1}$ ).

Figure 10 shows the effect of varying the diffusion coefficient on strontium movement. Small diffusion coefficient values result in little movement from the source area. Larger values result in an almost linear concentration profile leading away from the source area.

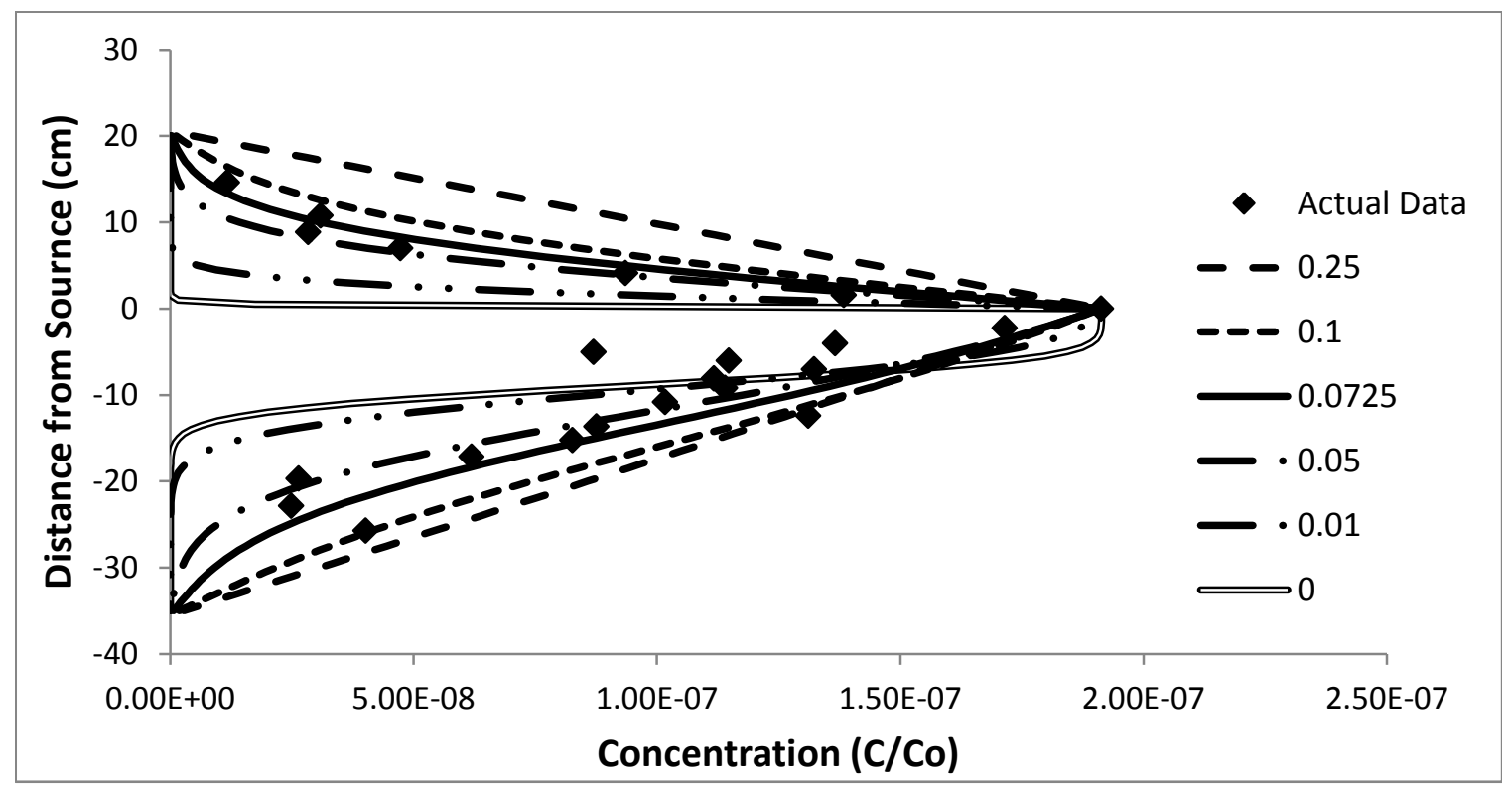

Figure 10: Model with varying diffusion coefficient (units in $\mathrm{cm} \mathrm{hr}^{-1}$ ). 
Figure 11 shows the effect of changing $\mathrm{K}_{\mathrm{d}}$ values on the strontium model. Changes in $\mathrm{K}_{\mathrm{d}}$ values had a greater impact on strontium distribution below the source than above the source, i.e., above the source the predicted lines were more similar and below the source, the predicted lines were wider apart. Furthermore, it appears that the $\mathrm{K}_{\mathrm{d}}$ construct does not fully describe all of the geochemical processes controlling strontium interaction with the sediment. This is suggested by the fact that no single line falls on the data or is parallel to the data. For example, our best estimate based on laboratory batch studies (Powell, 2010), $32 \mathrm{~L} \mathrm{~kg}^{-1} \mathrm{~K}_{\mathrm{d}}$ value, fits reasonably well with the data above the source, and the $<1.0 \mathrm{E}-7 \mathrm{C} / \mathrm{C}_{\mathrm{o}}$ data below the source. However, there appears to be other sorption processes involved for the small portion of the remainder of the dataset $(-15$ to $0 \mathrm{~cm} \mathrm{depth})$. Near the source term, there appears to be some process that increases strontium interaction with the sediment, or increases strontium retardation. One such process that may be involved is cation exchange (Powell, 2010). Cation exchange constants and kinetic terms are presently being developed and will be evaluated in future reactive transport models.

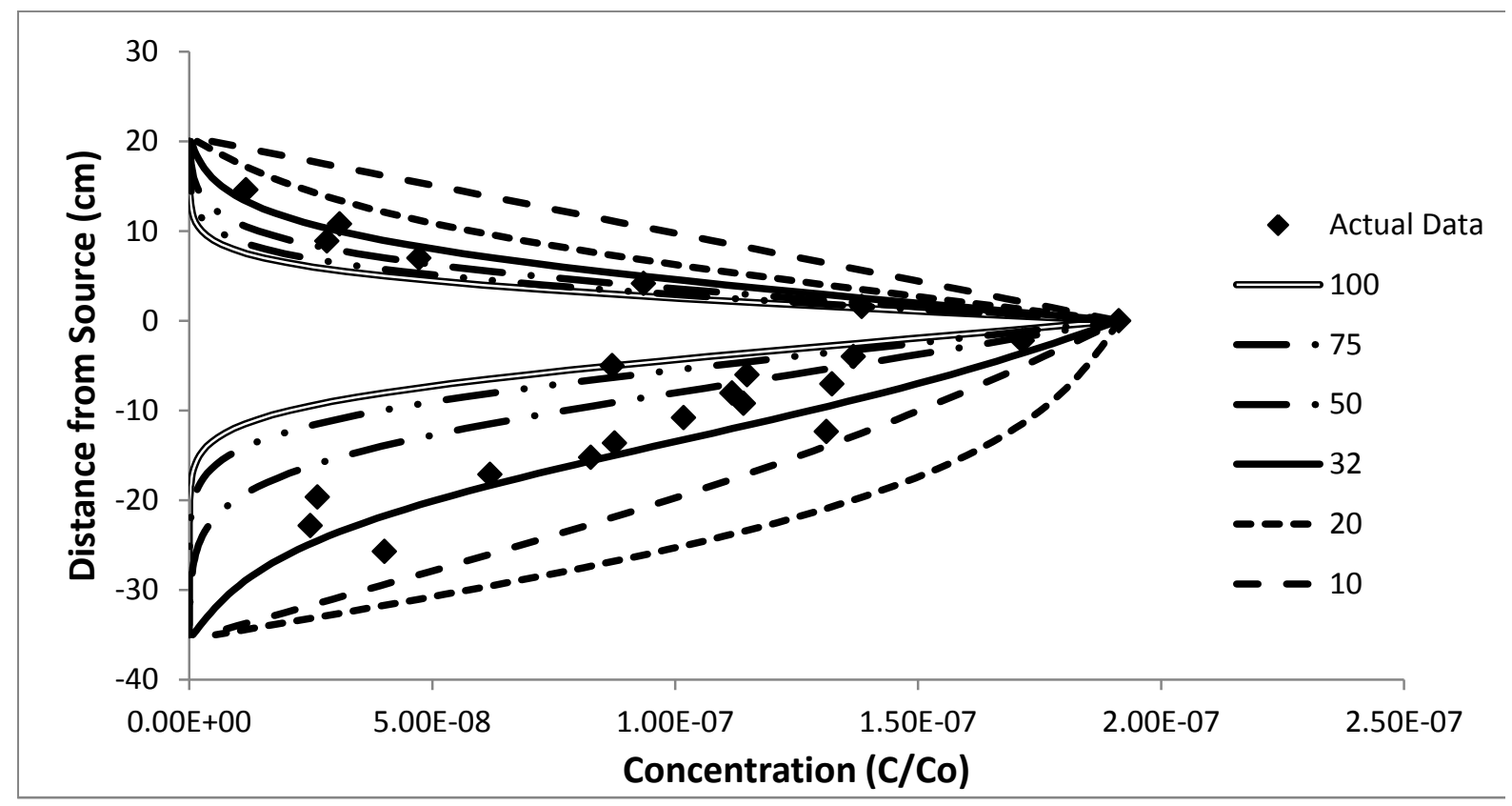

Figure 11: Model with varying $K_{d}$ values (units $\mathrm{L} \mathrm{kg}^{-1}$ ). While $32 \mathrm{~L} \mathrm{~kg}^{-1}$ is the best fit overall, the $\mathrm{K}_{\mathrm{d}}$ construct does not appear to be the onlv process influencing strontium interaction with the sediment.

\subsection{Conclusions}

Two modeling studies were conducted with existing data. The first data set had to do with $\mathrm{Np}$ sorption as a function of concentration (three orders of magnitude) and as a function of $\mathrm{pH}$ (four orders of magnitude of proton concentration). In this modeling exercise a very simple solution was identified by assuming that all sorption occurred only to the iron oxides in the sediment and that all the added $\mathrm{NpO}_{4}{ }^{-}$remained in the oxidized state and was not reduced to the $\mathrm{Np}(\mathrm{IV})$ state (as occurs rapidly with $\mathrm{Pu}(\mathrm{V})$ ). With rather limited input data, very good agreement between experimental and modeling results was observed.

The second model discussed in the report was developed to evaluate how well laboratory derived $\mathrm{K}_{\mathrm{d}}$ values perform in the real world and secondly, to do some sensitivity analyses of various hydrological and chemical processes that influence contaminant transport. The processes 
that sensitivity analyses were conducted on were diffusion coefficients, seepage velocity, and $\mathrm{K}_{\mathrm{d}}$ value. The best overall $K_{d}$ derived from the model fit to the data was $32 \mathrm{~L} \mathrm{~kg}^{-1}$, which was the same value as the previously measured $K_{d}$ in the traditional laboratory batch sorption studies. This was an unexpected result given the differences in experimental set up between batch test and the lysimeter flow through test, with particular differences between strontium adsorption and desorption processes occurring in the latter experiment and not in the former. This indicates that strontium adsorption and desorption rates must be very similar.

\subsection{References}

Arai, Y., Moran, P. B., Honeyman, B. D., and Davis, J. A. (2007). In Situ Spectroscopic Evidence for Neptunium(V)-Carbonate Inner-Sphere and Outer-Sphere Ternary Surface Complexes on Hematite Surfaces. . Environ. Sci. Technol. 41, 3940-3944.

Bethke, C. M., and Brady, P. V. (2000). How the Kd approach undermines ground water cleanup. . Ground Water 38, 435-443.

Davis, J. A., Coston, J. A., Kent, D. B., and Fuller, C. C. (1998). Application of the surface complexation concept to complex mineral assemblages. Environmental Science Technology 32, $2820-2828$.

Davis, J. A., Meece, D. E., Kohler, M., and Curtis., G. P. (2004). Approaches to surface complexation modeling of uranium(VI) adsorption on aquifer sediments. Geochem. Cosmochem. 68, 3621-3641.

Demirkanli, D. I., Molz, F. J., Kaplan, D. I., Fjeld, R. A., and Serkiz, S. M. (2008). A fully transient model for long-term plutonium transport in the Savannah River Site vadose zone: Plant water uptake Vadose Zone Journal 7, 1099-1109.

Dzombak, D. A., and Morel, F. M. M. (1990). "Surface Complexation Modeling: Hydrous Ferric Oxide," John Wiley and Sons, New York.

Freeze, R. A., and Cherry, J. A. (1979). "Groundwater," Prentice-Hall Inernational Limited, Englewood Cliffs, NJ.

Girvin, D. C., Ames, L. L., and Schwab, A. P. (1990). Neptunium Adsorption on Synthetic Amorphous Iron Oxyhydroxide. J. Colloid Interface Sci. 141, 67-78.

Jackson, M. L. (2005). "Soil Chemical Analysis: Advance Course, 2nd Edition," University of Wisconsin System, Madison, WI.

Jantzen, C. M., Bibler, N. E., Beam, D. C., and Pickett, M. A. (1993). " Characterization of the Defense Waste Processing Facility (DWPF) Environmental Assessment (EA) Glass Standard Reference Material," Rep. No. U.S. DOE Report WSRC-TR-92-346, Rev. 1, Westinghouse Savannah River Company, Aiken, SC.

Jantzen, C. M., Kaplan, D. I., Bibler, N. E., Peeler, D. K., and Plodinec, M. J. (2008). Performance of a buried radioactive high level waste (HLW) glass after 24 years. Journal of Nuclear Materials 378, 244-256. 
Kaplan, D. I., Serkiz, S. M., and Allison, J. (2010). Europium Sorption to Sediments in the Presence of Natural Organic Matter. Applied Geol. 25, 224-232.

Krupka, K. M., Kaplan, D. I., Whelan, G., Serne, R. J., and Mattigod, S. V. (1999). "Understanding Variation in Partition Coefficient, Kd, Values. Volume 1: The Kd Model, Methods of Measurement, and Application of Chemical Reaction Codes ". Office of Air and Radiation, Office of Solid Waste and Emergency Response, U.S. Environmental Protection Agency, Washington, DC., .

Nakayama, S., and Sakamoto, Y. (1991). Sorption of Neptunium on Naturally-Occuring IronContaining Minerals. . Radiochim. Acta. 52/53, 153-157.

Parson, R. (1982). Surface properties of oxides. J. Electroanal. Chem. 118, 2-18.

Powell, B., M. Lilly, T. Miller, and D. Kaplan (2010). "Iodine, Neptunium, Radium, Strontium and Technetium Sorption to Savannah River Site Sediments and Cementitious Materials," Rep. No. SRNL-STI-2010-00527, Savannah River National Laboratory, Aiken, SC.

Powell, B. A., Fjeld, R. A., Coates, J. T., Kaplan, D. I., and Serkiz, S. M. (2002). "Plutonium Oxidation State Geochemistry in the SRS Subsurface Environment," Rep. No. WSRC-TR2003-00035, Rev. 0. Westinghouse Savannah River Company, Aiken, SC.

Schindler, P. W., and Sposito, G. (1991). Surface complexation at (hydro)oxide surfaces. . In "Interactions at the Soil Colloid-Soil Solution Interface" (G. H. Bolt, M. F. DeBoodt, M. H. B. Hayes and M. B. McBride, eds.), pp. 115-145. Kluwer Academic Press, Boston, MA.

Seaman, J. C., and Kaplan, D. I. (2010). "Chloride, Chromate, Silver, Thallium and Uranium Sorption to SRS Soils, Sediments, and Cementitious Materials. ," Rep. No. SRNL-STI-201000493. Savannah River National Laboratory, Aiken, SC.

Serkiz, S. M., and Johnson, W. H. (1994). "Urnaium geochemistry in soil and groundwater at the F and H Seepage Basins " Rep. No. EPD-SGS-94-307, Savannah River National Laboratory, Aiken, SC.

Sims, D. J., Andrews, W. S., and Creber, D. A. M. (2008). Diffusion coefficients for uranium, cesium, and strontium in unsaturated prairie soil. Journal of Radioanalytical and Nuclear Chemistry 277, 143-147.

Smith, G. L. (1993). "Characterization of analytical reference Glass-1 (ARG-1)," Rep. No. PNL8992, Pacific Northwest National Laboratory, Richlnad, WA.

Sposito, G. (1984). "The surface chemistry of soils," Oxford University Press, New York, NY.

Turner, D. (1995). "A Uniform Approach to Surface Complexation Modeling of Radionuclide Sorption," Rep. No. CNWRA Rept. 95-001. Center for Nuclear Waste Regulatory Analyses, San Antonio, TX.

Westall, J. C. (1986). Reactions at the oxide-solution interface: Chemical and electrostatic models. In "Geochemical Processes at Mineral Surfaces. ACS Symposium Series 323.", pp. 54-78. American Chemical Society Washington, DC. 
Westall, J. C., and Hohl, J. (1980). A comparison of electrostatic models for the oxide solution interface. Advances Colloid Interface Sciences 12, 265-294.

Woolsey, G. B., Galloway, R. M., Plodinec, M. J., Wilhite, E. L., and Fowler, J. R. (1980). "Processing of Tank 15 sludge," Rep. No. USDOE Report DPST-80-361. 
SRNL-STI-2012-00052

Revision 0

Appendix A: Materials and Methods for the Neptunium Laboratory Sorption Study 
SRNL-STI-2012-00052

Revision 0

\subsection{Np Laboratory Batch Sorption Studies}

A compiled ${ }^{237} \mathrm{~Np}$ stock solution was used in this study and the following procedure was used in these studies to ensure that $\mathrm{Np}$ was in the +5 oxidation state $\left(\mathrm{NpO}_{2}{ }^{+}\right)$and that there were no other radiological impurities. ${ }^{237} \mathrm{~Np}$ (purchased from Isotope Products, Valencia, CA) was evaporated to dryness then the residue was brought up in approximately $5 \mathrm{~mL} 8.0 \mathrm{M}$ $\mathrm{HNO}_{3}$. Then $1.0 \mathrm{M}$ hydroxylamine hydrochloride $\left(\mathrm{NH}_{2} \mathrm{OH} \cdot \mathrm{HCl}\right.$, EMD Chemicals, ACS grade) and water were added to achieve a $3 \mathrm{M} \mathrm{HNO}_{3} / 0.3 \mathrm{M} \mathrm{NH} \mathrm{H}_{2} \mathrm{OH} \cdot \mathrm{HCl}$ solution. This solution was purified by extraction chromatography using Eichrom TEVA resin packed in a Bio-Rad poly-prep column. The $3 \mathrm{M} \mathrm{HNO}_{3} / 0.3 \mathrm{M} \mathrm{NH}_{2} \mathrm{OH} \cdot \mathrm{HCl}$ neptunium solution was loaded on a $2 \mathrm{~mL}$ column and washed with three column volumes of $3 \mathrm{M} \mathrm{HNO}_{3}$. The $\mathrm{Np}(\mathrm{IV})$ was eluted with $0.02 \mathrm{M} \mathrm{HCl}$ $+0.2 \mathrm{M} \mathrm{HF}$. The effluent was evaporated to dryness then redissolved in $1.0 \mathrm{M} \mathrm{HNO}_{3}$. The sample was brought up in $10 \mathrm{~mL}$ of $1.0 \mathrm{M} \mathrm{HNO}_{3}$ then evaporated to incipient dryness and redissolved in $5.0 \mathrm{~mL}$ of $1.0 \mathrm{M} \mathrm{HNO}_{3}$. An aliquot of the stock solution was evaporated to dryness on a stainless steel planchet and counted on the EG\&G Ortec Alpha Spectrometer (Octete PC Detectors). Alpha energies besides ${ }^{237} \mathrm{~Np}$ were not observed. The approximate ${ }^{237} \mathrm{~Np}$ concentration was determined using liquid scintillation counting and little ${ }^{233} \mathrm{~Pa}$ was observed. The fuming in $\mathrm{HNO}_{3}$ as performed at the end of the purification procedure will drive neptunium to the soluble pentavalent state. This is the stable oxidation state of neptunium under the experimental conditions. Therefore, experiments performed here can be assumed to be initially $\mathrm{Np}(\mathrm{V})$. The exact neptunium concentration in this solution was determined using ICP-MS calibrated with a National Institute of Standards and Technology (NIST) standard as discussed below.

Working Solution \#1 was created by pipetting an aliquot of the neptunium stock solution into a $100 \mathrm{~mL}$ Nalgene Teflon bottle and diluting with $2 \% \mathrm{BDH}$ Aristar Ultra $\mathrm{HNO}_{3}$ to give a working solution concentration of approximately $800 \mathrm{ppb}$. Working Solution \#2 was created by pipetting an aliquot of Working Solution \#1 with $2 \% \mathrm{BDH}$ Aristar Ultra $\mathrm{HNO}_{3}$ in a $250 \mathrm{~mL}$ polypropylene bottle to create a target concentration of approximately $50 \mathrm{ppb}$. Analysis on the ICP-MS calibrated against a NIST standard as described below gave concentrations of Working Solution $\# 1$ and Working Solution \#2 of $820 \mathrm{ppb}$ and $49.6 \mathrm{ppb}$, respectively. Calibration of the ICP-MS using the NIST standard is described in Section 5.2.

The sediments used for these experiments were obtained from the Savannah River Site. The subsurface sandy sediment will be referred to as the sandy sediment and the subsurface clayey sediment will be referred to as the clayey sediment. The clayey sediment was baked in an oven at $85^{\circ} \mathrm{C}$ overnight to remove excess moisture. The sandy sediment did not receive any treatment. Specific characteristics of each sediment are shown in Table 5. As the table indicates, both sediments are very low in organic matter. 
Table 5. Descriptions of SRS sediments used in this work (Powell et al., 2002).

\begin{tabular}{|l|l|l|l|l|l|l|}
\hline Name & Description & $\begin{array}{l}\text { Sand/Silt } \\
\text { /Clay } \\
(\mathrm{wt} \%)\end{array}$ & $\begin{array}{l}\text { Surface } \\
\text { Area } \\
\left(\mathrm{m}^{2} / \mathrm{g}\right)\end{array}$ & $\mathrm{pH}$ & $\begin{array}{l}\text { Organic } \\
\text { Matter } \\
(\mathrm{wt}-\%)\end{array}$ & $\begin{array}{l}\mathrm{Fe}(\mathrm{CDB}) \\
\mathrm{mg}_{\mathrm{Fe}} / \mathrm{s}_{\text {edi }}\end{array}$ \\
\hline $\begin{array}{l}\text { Subsurface } \\
\text { Sandy }\end{array}$ & $\begin{array}{l}\text { Subsurface } \\
\text { Yellow Sandy } \\
\text { Sediment Low } \\
\text { Organic Matter }\end{array}$ & $97 / 2 / 1$ & 1.27 & 5.1 & $<0.01$ & 15.26 \\
\hline $\begin{array}{l}\text { Subsurface } \\
\text { Clayey }\end{array}$ & $\begin{array}{l}\text { Subsurface Red } \\
\text { Clayey Burial } \\
\text { Ground } \\
\text { Sediment Low } \\
\text { Organic Matter }\end{array}$ & $58 / 30 / 12$ & 15.31 & 4.55 & NA & 7.06 \\
\hline
\end{tabular}

\subsection{ICP-MS Calibration Curves - Detection Limits}

A NIST, Standard Reference Material (NIST SRM 4341) was used to prepare a stock ${ }^{237} \mathrm{~Np}$ solution by dilution in $2 \%$ Aristar Optima $\mathrm{HNO}_{3}$. All volume additions were monitored gravimetrically. This working solution was then used to make a set of $0.01,0.05,1,2,5,10 \mathrm{ppb}$ standards by dilution using $2 \% \mathrm{HNO}_{3}$. Again all volume additions were monitored gravimetrically. These standards were used to calibrate the Thermo Scientific X Series 2 ICP-MS for quantification of ${ }^{237} \mathrm{~Np}$. A representative calibration curve for ${ }^{237} \mathrm{~Np}$ is shown in Figure 12 . The calibration data from Figure 12 is shown in Table 6. The instrument performance was monitored using ${ }^{232} \mathrm{Th}$ and ${ }^{238} \mathrm{U}$ as internal standards. The recovery of each sample during analysis was corrected based on the internal standard recovery. The internal standard recoveries remained within standard QA/QC protocols for the instrument (between $80 \%$ and $120 \%$ ).

The calibration curves were used to calculate the measured concentrations of neptunium in the samples being analyzed. The typical calibration curve shown in Figure 12 gave a minimum detectable limit of $1.8 \mathrm{ppq}$ (parts per quadrillion). This is consistent with an average minimum detectable quantity of $2 \mathrm{ppq}$ under the configuration of the instrument used for these measurements. Table 6 shows the goodness of fit of the calibration curve. 


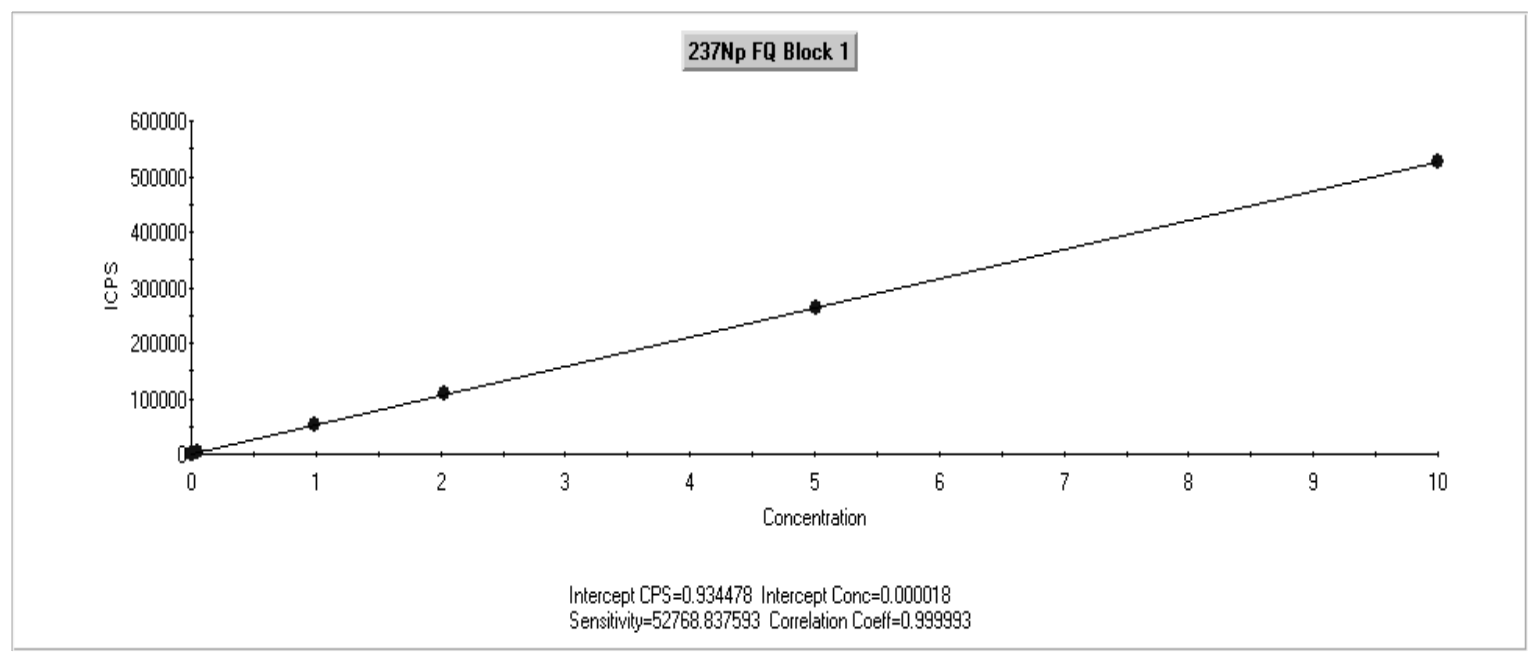

Figure 12. Screen capture of a typical ${ }^{237} \mathrm{~Np}$ calibration curve using Thermo PlasmaLab software to control the data collection and analysis. $\mathrm{R}^{2}=0.999993$, Intercept Conc. (Detection Limit) $=0.000018$ ppb.

Table 6. Example ICP-MS Calibration Curve Data

\begin{tabular}{|l|l|l|l|l|l|}
\hline Sample & $\begin{array}{l}\text { Actual NIST Np } \\
\text { Concentration }(\mathrm{ppb})\end{array}$ & $\begin{array}{l}\text { Measured Np } \\
\text { Concentration (ppb) }\end{array}$ & $\begin{array}{l}\text { Mean Np Ion } \\
\text { Counts Per } \\
\text { Second (ICPS) }\end{array}$ & Error & \% Error \\
\hline Blank & 0 & 0 & 1 & 0 & 0 \\
\hline $0.01 \mathrm{ppb} \mathrm{Np}$ & 0.01 & 0.01 & 528 & 0 & 0.82 \\
\hline $0.05 \mathrm{ppb} \mathrm{Np}$ & 0.05 & 0.05 & 2653 & 0 & 0.53 \\
\hline $1 \mathrm{ppb} \mathrm{Np}$ & 0.991 & 0.993 & 52410 & 0.002 & 0.2 \\
\hline $2 \mathrm{ppb} \mathrm{Np}$ & 2.028 & 2.06 & 108686 & 0.032 & 1.56 \\
\hline $5 \mathrm{ppb} \mathrm{Np}$ & 5.01 & 4.995 & 263575 & -0.015 & -0.3 \\
\hline $10 \mathrm{ppb} \mathrm{Np}$ & 9.998 & 9.999 & 527649 & 0.001 & 0.01 \\
\hline
\end{tabular}

\subsection{Preliminary Kinetic Sorption Tests}

Preliminary experiments were performed to determine the time needed to reach steady state sorption between the aqueous neptunium and the sorbed neptunium. This experiment was performed in $50 \mathrm{~mL}$ BD Falcon polypropylene centrifuge tubes. Replicate samples were prepared with sediment concentrations of $5 \mathrm{~g} / \mathrm{L}$ sediment and $25 \mathrm{~g} / \mathrm{L}$ sediment. A fifth tube was used as a control blank. The tubes were first filled with the appropriate mass of sediment then 4.5 $\mathrm{mL}$ of $0.1 \mathrm{M} \mathrm{NaCl}$ was added to produce a constant ionic strength of $0.01 \mathrm{M}$ in the final sample. This ionic strength was chosen to be similar to the ionic strength of the actual groundwater at the SRS. The use of this groundwater surrogate was used instead of actual groundwater to aid in experimental control. However, if actual groundwater was used, no changes in aqueous speciation of neptunium would have been expected. Next, $40 \mathrm{~mL}$ of distilled deionized water (DDI $\mathrm{H}_{2} \mathrm{O}$ ) was added along with $0.55 \mathrm{~mL}$ of Np Working Solution \#1 to obtain an initial neptunium concentration of $10 \mathrm{ppb}$. The $\mathrm{pH}$ was adjusted to 5.5 using $0.1 \mathrm{~N}$ and $0.01 \mathrm{~N} \mathrm{NaOH}$. The $\mathrm{pH}$ was measured using a VWR $\mathrm{Ag} / \mathrm{AgCl}$ glass electrode calibrated with $\mathrm{pH} 4,7$, and 10 
buffers (Thermo). The solutions were mixed using an end-over-end rotating tumbler at approximately eight rpm.

After 1, 3, 8, 24, and 48 hours, a $5 \mathrm{~mL}$ aliquot of each suspension was removed. Prior to removing the aliquot, a polyethylene transfer pipette was used to re-suspend any settled sediment particles and remove a homogenous suspension. This sample was then placed in a $15 \mathrm{~mL}$ BD Falcon polypropylene centrifuge tube and centrifuged in a Beckman Coulter Allegra X-22R Centrifuge at $8000 \mathrm{rpm}$ for 20 minutes. This was sufficient time to allow all particles $>100 \mathrm{~nm}$ to settle (Jackson, 2005). A $1 \mathrm{~mL}$ sample of the supernatant was then placed into an ELKay polystyrene culture tube and diluted with $2 \% \mathrm{BDH}$ Aristar Ultra $\mathrm{HNO}_{3}$ for analysis on the ICPMS. Then $2 \mathrm{~mL}$ of the remaining supernatant was placed into a Microsep 10,000 MWCO centrifugal filter. The samples were then centrifuged in a Beckman GS-6 centrifuge at $3000 \mathrm{rpm}$ for 2-3 minutes in order to wet the filter membrane and equilibrate neptunium with the membrane and the filtrate from this step was discarded. This pre-filtration step equilibrates the solution with the filter and washes the sodium azide preservation coating away. This results in a significant reduction in the loss of neptunium to the filter in the subsequent filtration. The sample was then centrifuged for an additional 20 minutes or until the majority of the sample passed through the filter. The filtrate was then transferred into an ELKay polystyrene culture tube and diluted with 2\% BDH Aristar Ultra $\mathrm{HNO}_{3}$ to determine the neptunium concentration using the ICP-MS. All volumes in the ICPMS sample were monitored gravimetrically.

\subsection{Sample Preparation - Baseline Batch Sorption Experiments}

Samples were prepared in $15 \mathrm{~mL}$ BD Falcon polypropylene centrifuge tubes. Each tube was first filled with the appropriate mass of sediment, filled with approximately $6 \mathrm{~mL}$ of DDI- $\mathrm{H}_{2} \mathrm{O}$ and $1 \mathrm{~mL}$ of $0.1 \mathrm{M} \mathrm{NaCl}$ and the $\mathrm{pH}$ was adjusted to approximately 5.5 with $0.1 \mathrm{~N}$ and $0.01 \mathrm{~N}$ $\mathrm{NaOH}$ and $\mathrm{HCl}$. All additions were monitored gravimetrically. The sediment suspension was then mixed end-over-end at eight rpm for 24 hours to equilibrate with the solution. The samples were then spiked with $\mathrm{Np}$ Working Solution \#1 (described above) to reach target initial concentrations ranging from $0.1 \mathrm{ppb}$ to $50 \mathrm{ppb}$. Finally, water was added to reach a $10 \mathrm{~mL}$ sample volume and the $\mathrm{pH}$ was again adjusted to a $\mathrm{pH}$ of 5.5. The mass of each addition of liquid and sediment to the sample tubes was monitored gravimetrically on Sartorius LA230S analytical balance.

\section{5 $\underline{\text { Sample Analysis }}$}

After the 48 hour equilibration period the $\mathrm{pH}$ of each suspension was measured using a VWR $\mathrm{Ag} / \mathrm{AgCl}$ glass electrode. Then a homogenous suspension was obtained by using a VWR $7 \mathrm{~mL}$ polyethylene transfer pipette to suspend the sediment particles. Approximately $1.5 \mathrm{~mL}$ of the suspension was transferred into $2 \mathrm{~mL}$ polypropylene centrifuge tubes and approximately $2 \mathrm{~mL}$ of solution was transferred into Microsep 10k Centrifugal filters. The $2 \mathrm{~mL}$ centrifuge tubes were spun at $5000 \mathrm{rpm}$ for 25 minutes in the VWR Galaxy 5D Centrifuge to settle particles greater than $100 \mathrm{~nm}$. An Eppendorf research grade pipette was used to draw off the supernatant, typically $1 \mathrm{~mL}$, and transfer it into an ELKay polystyrene culture tube. The mass of the transferred liquid was monitored gravimetrically. The sample was then diluted with $4 \mathrm{~mL}$ of $2 \%$ $\mathrm{BDH}$ Aristar Ultra $\mathrm{HNO}_{3}$ for ICP-MS analysis. The suspension in the Microsep 10k centrifugal filter was centrifuged in a Beckman GS-6 centrifuge at $3000 \mathrm{rpm}$ for 2-3 minutes in order to wet the filter membrane and equilibrate $\mathrm{Np}$ with the membrane then the filtrate was discarded. Then the remaining suspension was centrifuged for an additional 20 minutes and the effluent from the 
10k centrifugal filters was transferred into an ELKay polystyrene culture tube and diluted with $2 \% \mathrm{BDH}$ Aristar Ultra $\mathrm{HNO}_{3}$ for ICP-MS analysis. The neptunium concentration in all samples was determined on the ICP-MS.

The sediment concentration of $\mathrm{Np}$ was calculated using the following equation:

$$
[N p]_{\text {sed }}=\frac{\left([N p]_{a q u, o}-[N p]_{a q u}\right) V_{L}}{m_{\text {sed }}}
$$

Where: $\quad[N p]_{a q u, o}$ : Initial aqueous Np concentration, $\mathrm{ppb}$

$[N p]_{a q u}$ : Equilibrated (ICP-MS measured) aqueous $\mathrm{Np}$ concentration, $\mathrm{ppb}$

$[\mathrm{Np}]_{\text {sed }}$ : Equilibrated sediment $\mathrm{Np}$ concentration, $\mathrm{ppb}$

$V_{L}$ : Sample liquid volume, $\mathrm{mL}$

$m_{\text {sed }}$ : Sample sediment mass, $g$

The sediment water partitioning constant, $\mathrm{K}_{\mathrm{d}}$, was calculated via the following equation:

$$
K_{d}=\frac{[N p]_{\text {sed }}}{[N p]_{\text {aqu }}}
$$

The percent of $\mathrm{Np}$ sorbed was calculated via the following equation:

$$
f_{s}=1-\frac{[N p]_{a q u}}{[N p]_{a q u, o}}
$$

The $\mathrm{K}_{\mathrm{d}}$ equation (Equation 5) is numerically equivalent to the traditional $\mathrm{K}_{\mathrm{d}}$ equation proposed in ASTM D-4646 which has been used in previous sorption tests. 
SRNL-STI-2012-00052

Revision 0

6.0 Appendix B: Materials and Methods for the Strontium Lysimeter Field Study 
SRNL-STI-2012-00052

Revision 0

\subsection{Experimental}

Details of the lysimeter experiment are presented in Jantzen et al. 2008. As a part of a radionuclide migration research program, SRNL initiated a lysimeter project in 1978 to study the migration of radionuclide contaminates from various waste forms buried under actual field conditions. A HLW glass cylinder $(1.3 \mathrm{~cm}$ in diameter and $1.3 \mathrm{~cm}$ in length), representing a Defense Waste Processing Facility HLW glass, was buried in 1981. The HLW glass contained several radionuclides, including ${ }^{90} \mathrm{Sr}$. The glass was exposed to natural rainfall in the unsaturated zone for 11 years. The glass lysimeter was then capped to minimize groundwater infiltration for 5 years. The lysimeter was then core sampled and the sample left in a $16^{\circ} \mathrm{C}$ cooler for another 9 years. Therefore, the glass was exposed to weather conditions for 15 years and in contact with moist soil for 24 years.

\subsubsection{Fabrication of the HLW Glass}

Defense HLW was once an acid waste that was neutralized for storage in carbon steel tanks. The neutralization caused the waste to settle into a thick sludge component and low density salt supernates. The glass was made with Tank 15 waste which is a high alumina containing HLW waste sludge. The alumina is present as $\mathrm{Al}(\mathrm{OH})_{3}, \mathrm{AlOOH}, \mathrm{Al}(\mathrm{OH})_{4}^{-}$, and other soluble aluminum salts. The high aluminum content is detrimental to making a quality vitrified product at reasonable waste loadings (Woolsey et al., 1980).

A large sample of Tank 15 waste had been retrieved from the tank in 1978. Several aluminum removal processes were tested in the SRNL Shielded Cell Facility to remove the soluble alumina in water and/or excess $\mathrm{NaOH}$ (Woolsey et al., 1980). One test was performed in water only, two tests were performed in boiling 5 molar $\mathrm{NaOH}$, and the fourth test was performed with 3 molar $\mathrm{NaOH}$. The caustic treated sludge was mixed with water and centrifuged several times to "wash" the soluble salts out of the sludge in order to make a durable glass with a soluble salt level $<2 \mathrm{wt} \%$ on a dry basis. The alumina containing liquors can then be stabilized in cement.

At the end of the various Al dissolution steps and "washing" demonstrations the three caustic washed sludges were blended back together and reslurried with water (Woolsey et al., 1980). The sludge slurry was fed to a fluid-bed calciner with a bed temperature of $350^{\circ} \mathrm{C}$. The washed and dried Tank 15 sludge was mixed with Frit $211\left(\mathrm{SiO}_{2}=58.3, \mathrm{~B}_{2} \mathrm{O}_{3}=11.1, \mathrm{Na}_{2} \mathrm{O}=20.6, \mathrm{Li}_{2} \mathrm{O}=4.4\right.$, and $\mathrm{CaO}=5.6$ ) in a weight ratio of $35 / 65$ dried waste/sludge which is $\sim 28 \mathrm{wt} \%$ waste loading when all of the remaining insoluble nitrates, oxalates, and sulfates are destroyed at temperatures between the drying temperature of $350^{\circ} \mathrm{C}$ and the vitrification temperature of $1150^{\circ} \mathrm{C}$.

The glass was processed through a Joule heated melter in the Shielded Cell Facility in SRNL at a temperature of $1150^{\circ} \mathrm{C}$. Most of the glass was collected in $500 \mathrm{~mL}$ stainless steel beakers. At the end of two of the melt campaigns, glass samples were poured into small graphite molds and archived for leaching experiments. The filled glass canisters and the graphite molds were allowed to slow cool in a brick fort beside the melter to simulate the slow cooling of a DWPF type canister although a rigorous annealing schedule was not adhered to. The glass was not analyzed. One of the small graphite mold samples was the burial glass examined in this study.

The radionuclide concentrations in the glass were calculated from the radionuclides measured in the sludge (Woolsey et al., 1980) accounting for the sludge density, sludge washing percent, 
the calcine oxide factor, the waste loading, and the weight of the glass pellet. The primary radionuclide in the Tank 15 sludge was ${ }^{90} \mathrm{Sr}$.

\subsubsection{Burial and Retrieval of the HLW Glass}

The lysimeter consisted of an inverted 52-L bottomless carboy that was connected to a leachate collection reservoir. The lysimeter was filled with well-mixed subsurface sediment collected from a 4-m-deep pit in E-Area, SRS, from which the surface soil had been removed. The sediment used in this study was primarily collected from the vadose zone and contained no observable biological materials. The sediment had a $\mathrm{pH}$ of 6.3 , total Fe concentration of $1.6 \mathrm{wt}-$ $\%$, a sand, silt and clay content of 71,10 , and 19 wt- $\%$, respectively, and a clay-fraction consisting of kaolinite, hematite, goethite, gibbsite and quartz.

The glass pellet (described in section 3.3) was placed $21.6 \mathrm{~cm}$ below the lysimeter sediment surface on the centerline of the carboy in lysimeter M2. The lysimeter was left exposed to natural weather conditions for 11 years before being capped for an additional 4 years. During operation, leachate from the lysimeter was periodically sampled (May 1981 to December 1989) and analyzed for gross alpha, gross beta/gamma, and ${ }^{137}$ Cs. Samples were taken monthly from 1981 until June 1983 when the sampling frequency was changed to quarterly. After 1987 the sampling frequency was irregular and sometimes $\sim 6$ months. The data from this time period are erratic and not used in this study. The alpha and gross beta/gamma were measured with a Baird Instruments detector attached to a Scintillation Counter. A control lysimeter (M11) was also monitored and the alpha counts in the control lysimeter were often higher than the counts in the glass lysimeter. This is likely because the alpha emitters $\left({ }^{238} \mathrm{Pu}\right.$ and $\left.{ }^{239} \mathrm{Pu}\right)$ in the glass pellet are of very low concentration compared to the beta emitter $\left({ }^{90} \mathrm{Sr}\right)$. At the end of the exposure period, the lysimeter was cored and the core was cut into fourteen 1.25 to $2.5 \mathrm{~cm}$ slices. These depth

discrete sediment samples were acid digested and then analyzed for ${ }^{239 / 240} \mathrm{Pu}$ and ${ }^{137} \mathrm{Cs}$. As discussed above, the glass pellet was exposed to natural climatic conditions for $\sim 15$ years and was in contact with moist soil for 24 years.

\subsubsection{Characterization of the HLW Glass}

After the Tank 15 glass was recovered the following analyses were performed ${ }^{27}$.

- Contained X-ray Diffraction (CXRD) of the glass surface

- Analysed performed on a Bruker D8 Advanced X-Ray Diffractometer with $\mathrm{CuK}_{\alpha}$ radiation at $45 \mathrm{KV}$ and $40 \mathrm{~mA}$

- Contained Scanning Electron Microscopy (CSEM) of the glass/soil layer interface

- Analyses performed on a LEO-440 Scanning Electron Microscope. The Energy

Dispersive Spectra (EDS) were acquired using an Oxford Inca microanalysis system

- The sample was embedded in epoxy and sectioned perpendicular to the glass/soil interface

- Whole element chemistry of the bulk glass by

- Dissolution by $\mathrm{Na}_{2} \mathrm{O}_{2}$ with an $\mathrm{HCl}$ uptake followed by Inductively Coupled Plasma (ICP) - Emission Spectroscopy (ES) for Al, B, Ba, Ca, Ce, Cr, Cu, Fe, La, $\mathrm{Li}, \mathrm{Mg}, \mathrm{Mn}, \mathrm{Mo}, \mathrm{Ni}, \mathrm{Si}, \mathrm{Sn}, \mathrm{Sr}, \mathrm{Ti}$, and U and ICP-Mass Spectroscopy (MS) for Th 


\section{- Dissolution by $\mathrm{HCl} / \mathrm{HF}$ bomb followed by ICP-ES for $\mathrm{Na}$, Zn, and $\mathrm{Zr}$}

Anions were not measured as the anion content of the glass was predicted to be very low from analysis of the Tank 15 sludge (Woolsey et al., 1980) and analysis of the washed/dried sludge (Woolsey et al., 1980). Glasses were analyzed in duplicate and both the Environmental Assessment (EA) glass (Jantzen et al., 1993) and the ARG-1 glass (Smith, 1993) were used as glass standards. 


\section{Distribution:}

\section{Savannah River Site}

R. S. Aylward, 773-42A - Rm. 281

B. T. Butcher, 773-43A - Rm.212

L. B. Collard, 773-43A - Rm.207

D. A. Crowley, 773-43A - Rm.216

G. P. Flach, 773-42A - Rm. 211

R. A. Hiergesell, 773-43A - Rm.218

D. Li , 999-W - Rm. 216

D. I. Kaplan, 773-43A - Rm.215

J. J. Mayer, 773-42A - Rm. 242

K. A. Roberts, 773-43A - Rm.225

F. G. Smith, III 773-42A - Rm.178

G. A. Taylor, 773-43A - Rm.230

Clemson University, 342 Computer Court, Anderson, SC 29625-6510

Brian A. Powell

Todd J. Miller

(1 file copy \& 1 electronic copy), 773-43A - Room 217 